Review

\title{
Chemomechanical Polymers as Sensors and Actuators for Biological and Medicinal Applications
}

\author{
Hans-Jörg Schneider ${ }^{1, *}$, Kazuaki Kato ${ }^{1,3}$ and Robert M. Strongin ${ }^{2, *}$ \\ ${ }^{1}$ FR Organische Chemie der Universität des Saarlandes, D-66041 Saarbrücken, Germany \\ 2 Department of Chemistry, Portland State University, Portland, OR, 97201, USA \\ ${ }^{3}$ Department of Advanced Material Science, Graduate School of Frontier Sciences, The University of \\ Tokyo, Chiba 277-8562, Japan; E-mail: kato@molle.k.u-tokyo.ac.jp \\ * Authors to whom correspondence should be addressed; E-mails: ch12hs@ rz.uni-sb.de; \\ strongin@pdx.edu
}

Received: 8 August 2007 / Accepted: 21 August 2007 / Published: 27 August 2007

\begin{abstract}
Changes in the chemical environment can trigger large motions in chemomechanical polymers. The unique feature of such intelligent materials, mostly in the form of hydrogels, is therefore, that they serve as sensors and actuators at the same time, and do not require any measuring devices, transducers or power supplies. Until recently the most often used of these materials responded to changes in $\mathrm{pH}$. Chemists are now increasingly using supramolecular recognition sites in materials, which are covalently bound to the polymer backbone. This allows one to use a nearly unlimited variety of guest (or effector) compounds in the environment for a selective response by automatically triggered size changes. This is illustrated with non-covalent interactions of effectors comprising of metal ions, isomeric organic compounds, including enantiomers, nucleotides, aminoacids, and peptides. Two different effector molecules can induce motions as functions of their concentration, thus representing a logical AND gate. This concept is particularly fruitful with effector compounds such as peptides, which only trigger size changes if, e.g. copper ions are present in the surroundings. Another principle relies on the fast formation of covalent bonds between an effector and the chemomechanical polymer. The most promising application is the selective interaction of covalently fixed boronic acid residues with glucose, which renders itself not only for sensing, but eventually also for delivery of drugs such as insulin. The speed of the responses can significantly increase by increasing the surface to volume ratio of the polymer particles. Of particular interest is the sensitivity increase which can be reached by downsizing the particle volume.
\end{abstract}


Keywords: chemomechanical polymers, hydrogels, molecular recognition, supramolecular complexes , artificial muscles, glucose sensors

\section{Introduction}

Sensors are increasingly being used for monitoring changes in environmental conditions in a fully automated manner. This includes detecting the levels of chemical compounds in living systems. In most applications, a sensing unit is only one component of an operating system which responds to the sensor signal by a predetermined action, e.g. by correcting the $\mathrm{pH}$ of a medium by adding neutralizing agents. A unique feature of chemomechanical polymers is that they function simultaneously as both sensors and actuators. These intelligent materials can be designed to respond to changes in external conditions via macroscopic or microscopic motions, which may then be used to control electric circuits or to open or close, e.g., vessels for the release or uptake of different agents. The major advantage in comparison to traditional control systems is that chemomechanical polymers can operate without any additional devices such as transducers or transmitters, and without any external power supply. These new materials can be fabricated in a variety of ways, down to the micro- or nano scale, or as thin films, to afford the added advantages of enhanced sensitivity and speed of response. The field is expected to expand considerably after chemists have, in the framework of supramolecular chemistry, developed the principles of molecular recognition, which, until now have been studied mainly in solution [1]. Smart materials, into which suitable recognition sites are incorporated, hold much promise for a manifold of applications [2], including drug delivery [3], detoxification, control of biological functions in the body, artificial muscles [4], etc. Scheme 1 illustrates the mechanisms involved in expansion of hydrogels by the uptake of guest molecules $G$ which bind non-covalently to acceptor sites $A, B, C$, etc., on the polymer backbone.

Scheme 1. Expansion of hydrogels by uptake of guest molecules $G$ and of water for solvation.

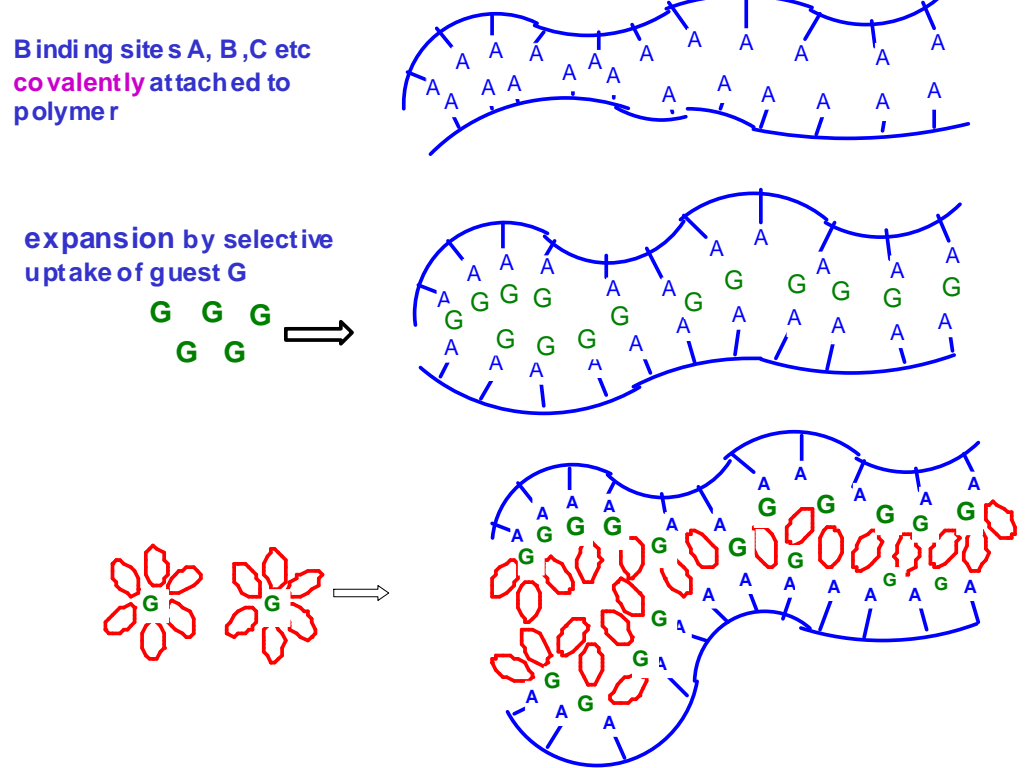


The motions of flexible polymers can be activated by voltage (Electrically Activated Polymers, EAP's) [5], particularly in the form of ionic polymer-metal composites (IPMC's) [6], to furnish efficient artificial muscles. Other related systems are based on conducting polymers [7] and stimulation by light [8], by temperature [9] or by other external signals [2,10]. In gels, swelling or contraction can generally be induced by a large range of external stimuli, often as the result of phase transitions [11,12]. Although gels can assume a multitude of states [13], a general distinction can be made between a loose swollen state, stable at lower temperatures, and a shrunken, collapsed state, which results, for example, from a temperature increase. In the swollen state a target molecule such as a drug, can adsorb preferentially by single contacts with loose receptor sites of the polymer network, whereas in the shrunken state multipoint interactions can lead to higher affinity [12]. Imprinting techniques, in which a target molecule serves to generate complementary binding cavities [14] have also been applied to gels [15]. It has been shown that by polymerization after imprinting and subsequent release of the substrate molecule in the swollen state, the collapsed state can retain sufficient memory to bind the ligand with increased selectivity, although the effects until now were rather modest [16,17]. In the present review, which tries to cover the literature until the end of 2006, we focus on how chemomechanical polymers can respond to specific external chemical signals, mainly by size changes.

\section{Chemomechanical materials triggered by $\mathrm{pH}$ and alkali salt changes}

The most often explored chemically stimulated size changes of polymers are those due to changes in the acidity of the surrounding medium $[18,19]$. Generally, most polymers bearing ionizable groups show expansion upon ionization; e.g., gels containing amino groups will swell at lower $\mathrm{pH}$. Katchalsky, Kuhn and others [20] described in 1950 the reversible viscosity increase of a polyacrylic acid solution under basic conditions. This was ascribed primarily to chain unfolding produced by the loss of hydrogen bonds upon protonation of the carboxylate groups, and by a chain elongating via repulsion between the carboxylate anions at higher $\mathrm{pH}$.

Scheme 2. Structures of some chemomechanical polymers (I: polymethacrylic acid with supramolecular binding functions, II: chitosam, III: polyallylamine).
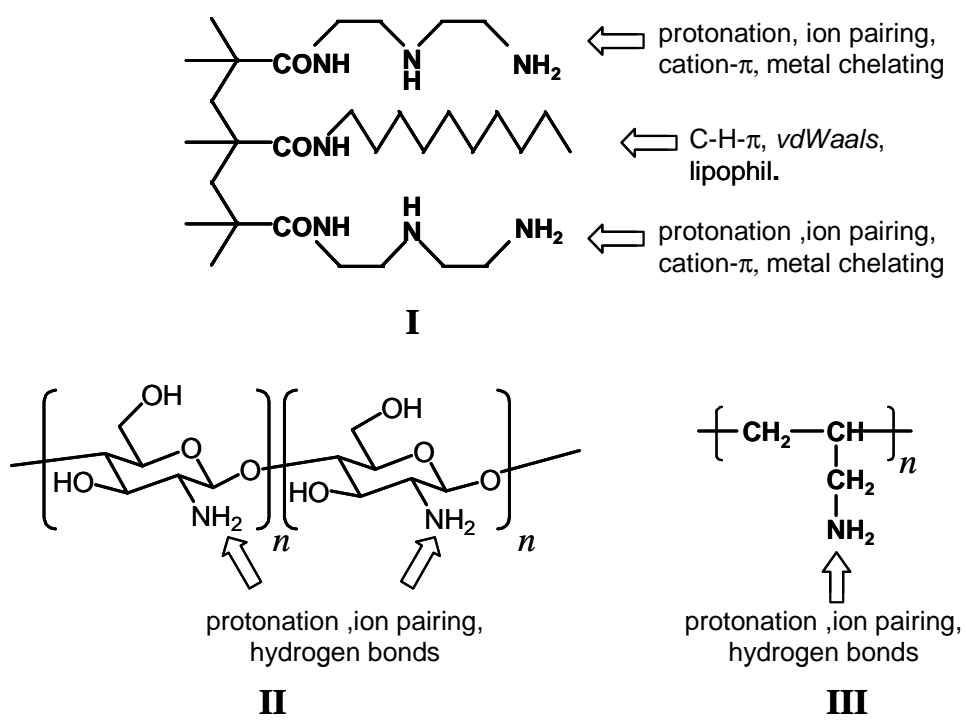
In hydrogels (Scheme 2) a volume increase occurs by the uptake of water which is needed for the solvation of developing cationic or anionic sites, which is invariably accompanied by the import of the associated counterions (see also Scheme 1). In polyelectrolyte gels, swelling and contraction can also be produced electrically (as in electrodialysis), thus allowing the design of both $\mathrm{pH}$-operated and microelectro-machines [21]. Several chemomechanical elements in particular for $\mathrm{pH}$ sensing have been already described [22].

Gels containing randomly distributed both positively and negatively charged groups can be characterized by more than two, either collapsed or swollen, phases. They may exhibit maximumswelling at two different $\mathrm{pH}$ values, which depend on the relative $\mathrm{pK}$ values [13b]. Thus, chitosan-polyacrylic acid gels exhibit three maximum expansions at pH 3, pH 6 and pH 8 [23]. Hydrogels derived from phosphorylcholine and polymethacrylic acid or ester form networks which exhibit swelling only at higher $\mathrm{pH}$. This is ascribed as shown in Scheme 3to the intramolecular hydrogen bonded cross-links of the carboxyl groups, and allows pH-dependent drug release [24]. In some gels undergoing phase transitions within a narrow range of temperature and also $\mathrm{pH}$ values, there is no stable intermediate between a swollen and a collapsed state [25,26]. Gels derived from poly(methacrylic acid /nitrophenyl acrylate) exhibit swelling proportional to the solution pK(a)'s of their functional groups [27].

Chitosan gels (Scheme 2) are obtained using simple inorganic or organic acids [28]; under acidic conditions they slowly dissolve [29] in absence of crosslinker [30], but under close to neutral condition chitosan hydrogels are stable enough for many applications. Semi-interpenetrating hydrogel networks of chitosan and polyacrylamide show increased swelling below $\mathrm{pH}=7$ [31]. Copolymers containing galactosamine and glutamate contract under acidic conditions [32]. Similarly, semi-interpenetrating networks of cross-linked copolymer acrylamide/acrylic acid polyallylamine can serve as effective $\mathrm{pH}$ stimulated drug delivery system [33]. Two-component crosslinked chitosan derivatives show swelling at $\mathrm{pH} 7.4$ and above due to ionization of the carboxylic acid groups in the gel [34]. A strong temperature dependence of $\mathrm{pH}$ triggered hydrogels composed of poly(2-ethyl-2-oxazoline) and chitosan was reported [35]. Microgels from poly(methacrylic acid-co-nitrophenyl acrylate) were selectively derivatized with carboxylic acid, glutamic acid, hydroxamic acid, sulfonic acid, and ethanol functional groups, yielding $\mathrm{pH}$ - and $\mathrm{NaCl}$ induced swelling responses and drug loading, proportional to the solution $\mathrm{pK}(\mathrm{a})$ 's of their functional groups [36]. Polyallylamine III, after crosslinking, exhibits a sharp swelling at $\mathrm{pH} 7$, although its $\mathrm{pK}$ value of 9.7 [37] would suggest a jump at higher $\mathrm{pH}$; this was explained by counteracting ion pairing with the special hydroxyphenylsulfonate used in this study [38].

The hydrogel I derived from the reaction of poly(methyl)methylacrylate (PMMA), diethylenetriamine and dodecylamine (Scheme 2) provides both $\mathrm{pH}$-sensitive and lipophilic binding groups, It appears to be the only known gel which displays a symmetric $\mathrm{pH}$ profile above and below pH 7 (Figure 1) [39]. Xanthan-chitosan gels were reported to be sensitive not only to high pH with a maximum swelling at $\mathrm{pH} 10$, but to some degree also at $\mathrm{pH}$, where, however, the gel dissolves in the course of swelling [40]. 
Figure 1 a) Size changes of a PMMA-derived hydrogel (I, Scheme 1) as function of $\mathrm{pH}$; calculated maximum volume change $390 \%$; in $0.05 \mathrm{M}$ phosphate buffer (circles), and in $0.5 \mathrm{M}$ sodium chloride (triangles); b) $\mathrm{pH}$ expansion profiles at different salt concentrations; in $0.5 \mathrm{M}(\bullet-\mathrm{a}), 0.05 \mathrm{M}(\mathrm{D}-\mathrm{b})$, and $0.025 \mathrm{M}(\tilde{\mathrm{N}}-\mathrm{c})$ sodium chloride solution, respectively, and in water with very dilute $\mathrm{HCl}$ or $\mathrm{NaOH}(\boldsymbol{\nabla}-\mathrm{d})$. Schneider, $\mathrm{H}$. J.; Liu, T. J.; Lomadze, N. Molecular recognition in a supramolecular polymer system translated into mechanical motion. Angew. Chem.-Int. Edit. 2003, 42, 3544-3546. Copyright Wiley-VCH Verlag GmbH \& Co. [39a].
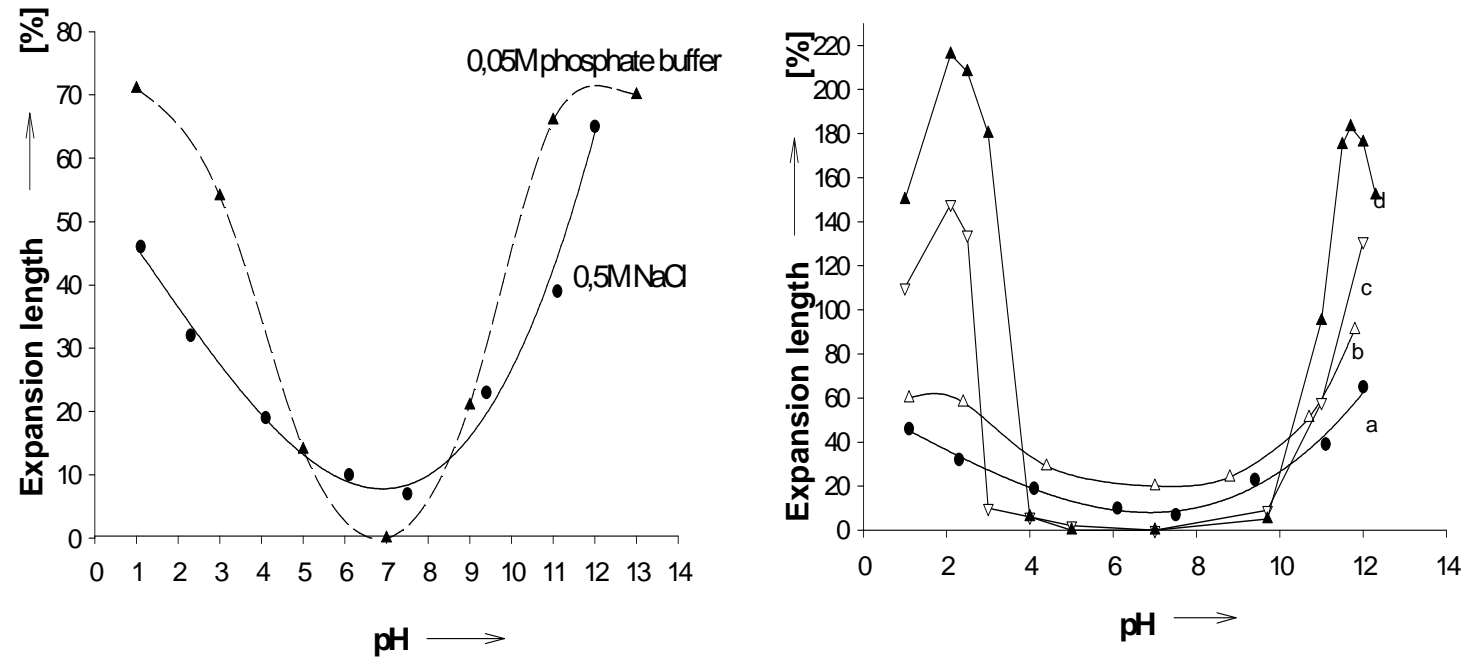

The chemomechanical response to varying $\mathrm{pH}$ depends strongly on the ionic strength of the medium (Figure 1b) [41]. Independent measurements indicate that similar expansions, for example, at pH 2 and 12 in presence of salts (Figure 1a) occur with related sodium chloride concentrations alone at neutral $\mathrm{pH}$. Thus, the lower and higher $\mathrm{pH}$ effects are also due to increased ionic strength by the acid or base concentrations at such $\mathrm{pH}$ values. [39] In accord with this, it was found that polysaccharide-derived gels decrease their swelling with an increase in the ionic strength of the salt solutions, due to charge screening effect for monovalent cations, as well as to ionic crosslinking for multivalent cations [42].

Contraction of hydrogels instead expansion is expected to occur via crosslinking, which can be the result of non-covalent ion-pairing ,as in cases where anions bind to cationic sites of a polymer backbone (Scheme 3). These sites may be produced as a result of the protonation of polyamines, thereby affording volume changes attributable to $\mathrm{pH}$ as well as the degree of condensation by different anions.

Scheme 3. Contraction: ionic crosslinking decreases in the order $\mathrm{SO}^{4-}>\mathrm{Cl}^{-}>\mathrm{AcO}^{-}$anions [48].
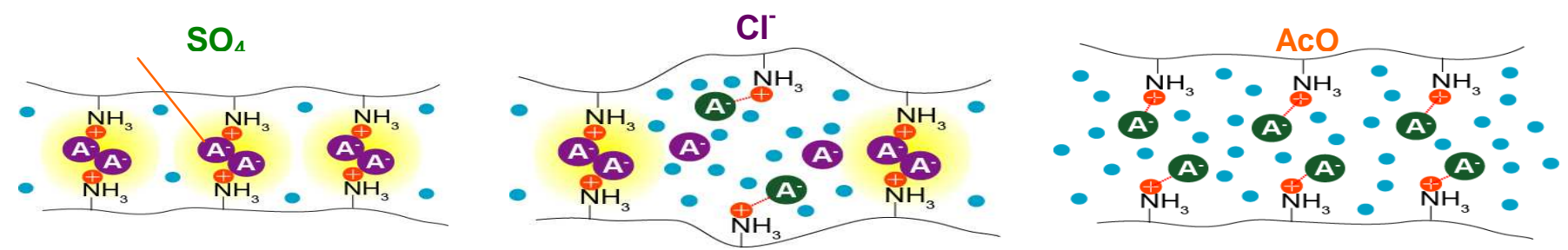
Apart from various crosslinking interactions with different anions there are also salt effects due to changes in ionic strength [43]. An example is the self assembly of beta-hairpin peptides into hydrogel nanostructures consisting of semiflexible fibrillar assemblies [44]. Circular dichroism spectroscopy indicates that in the absence of salt the peptides are unfolded. Increasing the ionic strength of the medium screens electrostatic interactions between charged amino acids within the peptide promoting subsequent beta-hairpin formation. Adsorption affinities for various substrates decrease by orders of magnitude with increasing salt concentration.[45] A moderate selectivity with respect to different alkali salts is observed with hydrogel I as illustrated in Scheme 4 [39].

Scheme 4. Volume changes ([\%]) induced by different anions on the PMMA-derived polymer I; $[\mathrm{NaX}]=0.10 \mathrm{M}$; left bars (always expansion): in pure water, $\mathrm{pH} 7.3$; right bars (partially contraction), in presence of $0.02 \mathrm{M}$ phosphate buffer, $\mathrm{pH}$ 7.0. Copyright WileyVCH Verlag GmbH \& Co. [39a].

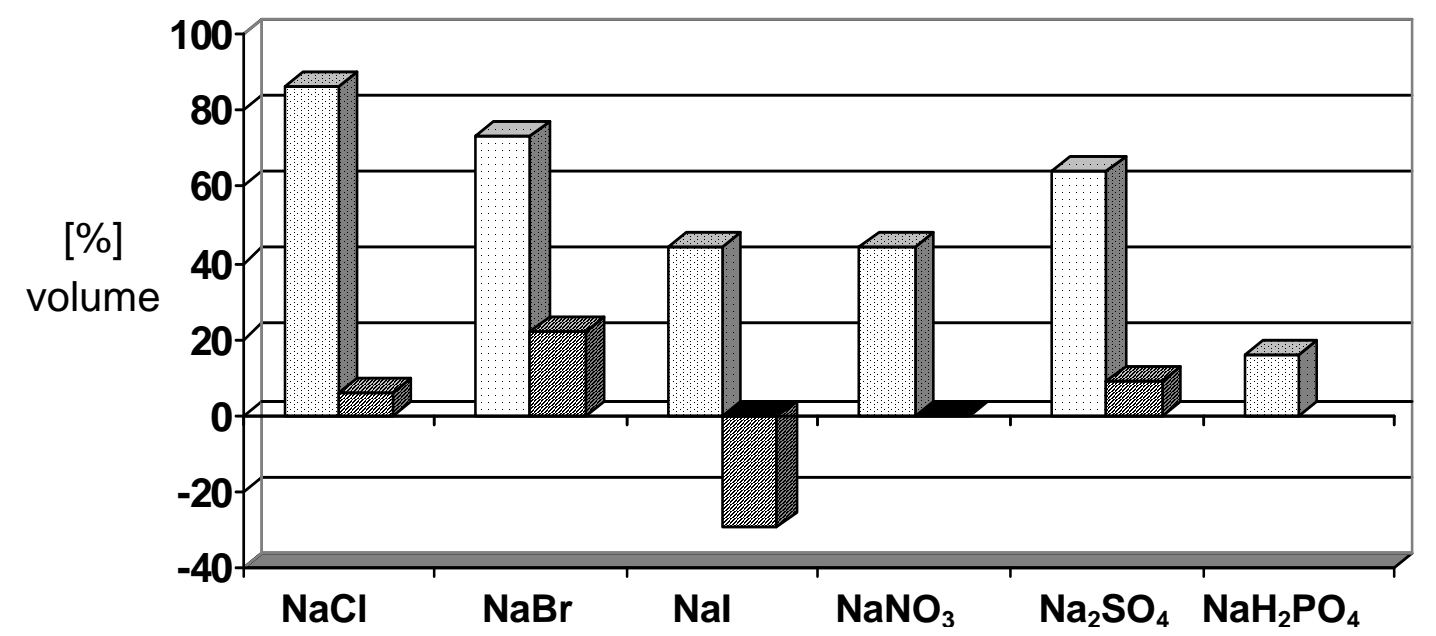

The partially reversed effects in the presence of sodium phosphate will be discussed below in the context of cooperativity effects. It should be noted that reverse contraction after the expansion of ionic polymers requires treatment with another salt or buffer to replacement the counterion neutralizing the backbone charge.

Swelling of chitosan II is also not only a function of $\mathrm{pH}$, but also of the acid used. Expansion stimulated by acetic acid begins at $\mathrm{pH} 6.2$, which is close to the pKa of chitsoan. In contrast, acids such as hydrochloric acid or phosphoric acid cause chitosan II to expand at lower $\mathrm{pH}$. The specific effect of the polyvalent phosphoric acid can be tentatively ascribed to ionic crosslinking acting to counteract expansion. Ionic cross-linking with concomitant gel contraction occurs only in the presence of anions, while free acids, formed depending on their $\mathrm{pK}$ values, cause expansion. Monocarboxylic acids such as benzoic or cyclohexanoic acid behave like acetic acid, whereas dicarboxylic acids cause size changes in polymers based on the chain length separating their carboxylic moieties: glutaric and succinic acid, having similar $\mathrm{pK}$ values as the monoacids, behave as such, whereas oxalic, tartraric and malonic acids, due to the proximity of their carboxyl groups with low $\mathrm{pK}$ values, promote reduced chemomechanical effects, again ascribed to counteracting anion-based crosslinking, as in the case of phosphate [48]. Anion effects can to some degree be selective without the introduction of selective 
binding groups into the gels. An alternative used not for chemomechanical properties but for the sensing of different phosphate derivatives is based on fluorescent artificial receptors, which, upon guest-binding, can dynamically change the location between an aqueous cavity and hydrophobic fibers under the semi-wet conditions of a supramolecular hydrogel, as observed by confocal laser scanning microscopy [46].

Chitosan obtained by ionic crosslinking with either triphosphate TPP or polyphosphate PP was found to swell to varying degrees which depend on the mode of preparation. The swelling at high $\mathrm{pH}$ was ascribed to deprotonation of the chitosan amine groups with disruption of the cross-linking salt bridges. However, if the gels with TPP or PP were prepared at $\mathrm{pH} 6.8$ the $\mathrm{pH}$-induced swelling was small, whereas gels prepared at $\mathrm{pH} 1.2$ showed large swelling above $\mathrm{pH}$ 8. In PAH III gels, crosslinked with glutardialdehyde, iodide induces a larger contraction compared to chloride. It was concluded that the higher polarizability of iodide ions result in enhanced ion-pair formation and thereby decreased osmotic pressure, resulting in collapse of the gel [47].

\section{Water content changes}

As mentioned above, the uptake or release of water molecules plays a decisive role in the size changes of chemomechanical hydrogels. Dry hydrogels take up copious amounts of water (up to $99 \%$ e.g. in case of polyallylamine [48]). Exposure of the swollen polymer to different effectors in aqueous solution or to $\mathrm{pH}$ changes can lead to significant additional weight and volume increases. It is known that water transport through gels is significantly affected by the $\mathrm{pH}$ of the environment [49]. Chitosan hydrogels grafted with lactic or glycolic acid were characterized by FT-IR and differential scanning calorimetry (DSC), and the presence of three different water types was proposed [50]. Carboxymethylcellulose gels exhibited water uptake as function of the cross-linkers used; after sulfating the gels are $\mathrm{pH}$-sensitive. The water uptake of these gels was studied by FT-IR spectra; hydrogen bond formation between the chains was proposed to explain the correlation between water uptake properties and the chemical composition of the gels [51]. Albumin gels displayed at the isoelectric point a minimal amount of swelling, and expansion above and below the pI [52]. In crosslinked chitosan/polyether hydrogels the total water content and the amount of bound water is related to the $\mathrm{pH}$ value of the environment. The diffusion coefficient from the kinetics correlates to the water state within the swollen hydrogel, and likely is related to the relative composition of bound and nonbound water [53]. Hydrogels derived from fluorenyl-ala-ala dipeptides release $40 \%$ of their water upon addition of the strong binding ligand vancomycin [54].

Gravimetric measurements allow one to quantify the role of water uptake and/or release. Scheme 5 shows the weight increase which accompanies effector absorption in PMMA polymer I. Independent measurements of water content before and after expansion establish that the weight increase is almost entirely due to water uptake. At the same time Scheme 5 illustrates the abovementioned water uptake by protonation and deprotonation at low and high $\mathrm{pH}$. In comparison to $\mathrm{pH}=7$ there is a water content increase by a factor of $\mathrm{f}=26 \pm 1$. The swelling induced by other effectors reflects the need of these molecules inside the gel for effector solvation, leading to a expansion which goes far beyond the weight and volume increase which would be produced by the effector alone [39]. 
Scheme 5. Weight increase compared to expansion. Values scaled per mg of wet PMMAderived polymer $\mathbf{I}$, in $\mathrm{mg}$ of total weight increase due to water and effector, and in $\mathrm{mg}$ increase due to effector alone (upper limit as estimated from absorption measurements and complexometry); volume expansion $\Delta \mathrm{v}$ (from $1 \mathrm{~mm}^{3}$ wet), average from length and width increase. Weight increase is within the error due to water content increase. Copyright Wiley-VCH Verlag GmbH \& Co. [39a].

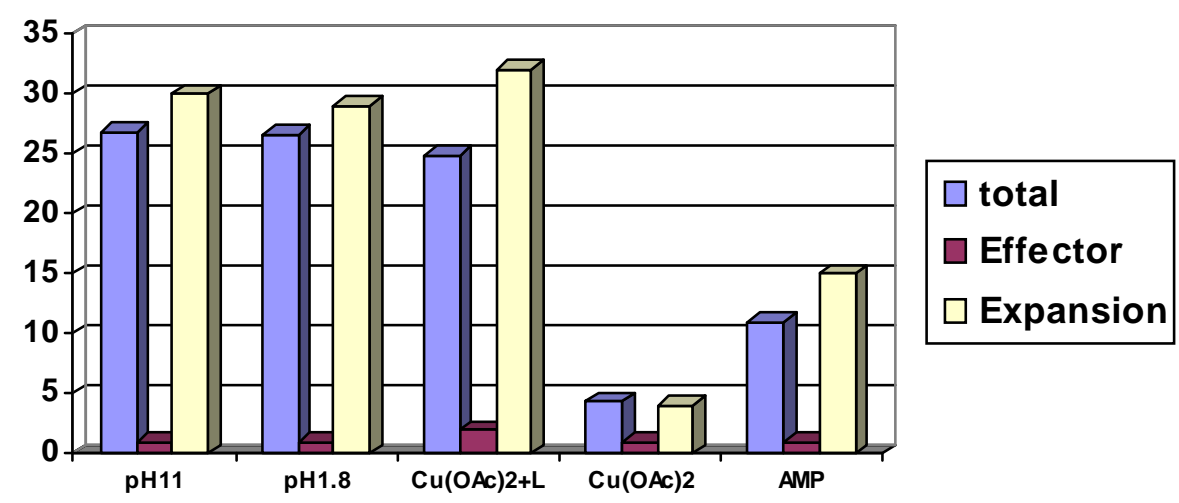

\section{Kinetics, concentration effects and sensitivity}

The speed of volume changes are essentially a function of the effector diffusion into the gels, as described by Fick's laws. It has been shown that expansion of xanthan-chitosan-derived gels upon $\mathrm{pH}$ changes seems to be mainly controlled by the diffusion of mobile ions, except that at $\mathrm{pH}$ values below 10 the degree of ionization during swelling also may affect the swelling rate [55,56]. Figure 2 illustrates that with the PMMA derived polymer I the kinetics of both expansion and the fully reversible contractions follow pseudo first-order equations, the same holds for the corresponding ab- and desorption of the effectors [39].

Figure 2. Kinetics of expansion and desorption (action of AMP on polymer I, least square fit to first order equation. Schneider, H. J.; Liu, T. J.; Lomadze, N. Molecular recognition in a supramolecular polymer system translated into mechanical motion. Copyright Wiley-VCH Verlag GmbH \& Co. [39a].
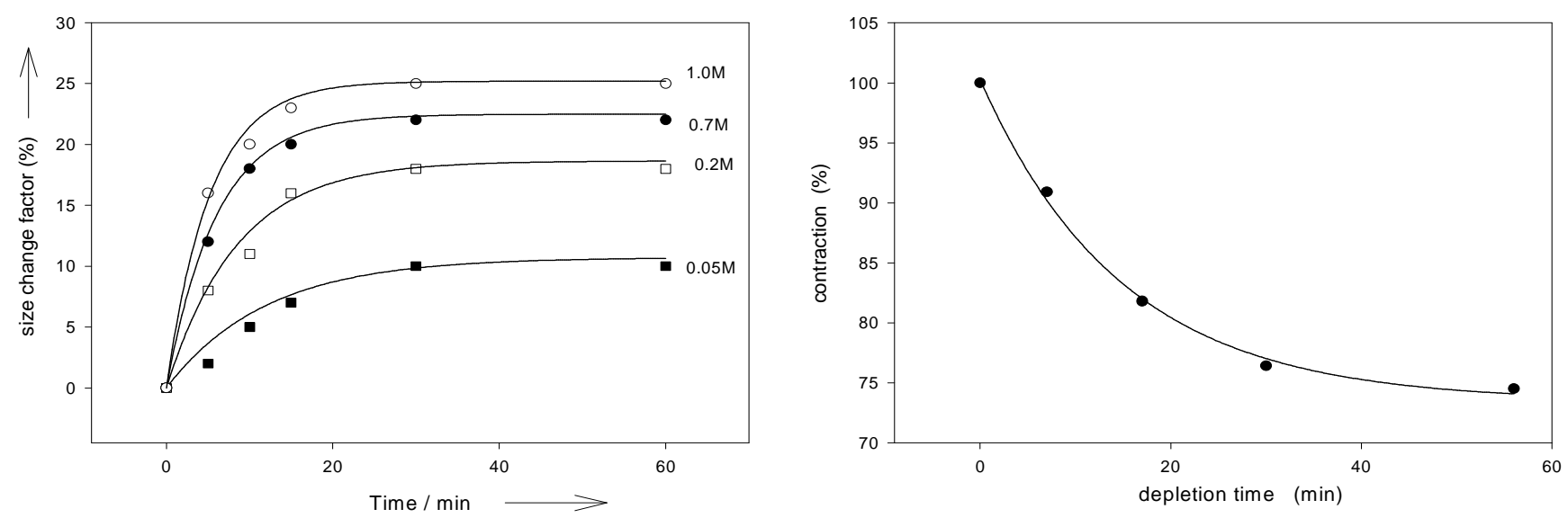
The size and shape of the polymer particles have a distinctive influence on the expansion and contraction of the chemomechanical materials. The rate of volume changes depends on the effector concentration gradients, the speed of effector diffusion into the particles, and therefore also on the surface to volume ratio. Thus, film pieces of chitosan gel show with chitosan II that effectorinduced expansion rates increase along with the surface to volume ratio S/V (Figure 3) [48].

Figure 3. Expansion kinetics, and surface to volume $\mathrm{S} / \mathrm{V}$ effects of chitosan II; elongation induced by $50 \mathrm{mM}$ L-histidine and $0.1 \mathrm{M}$ acetic acid, in $30 \mathrm{mM}$ phosphate buffer at $\mathrm{pH}$ 5.0. Approximate "half-life" time $\mathrm{t}_{1 / 2}$ for $50 \%$ of the maximum expansion: $\mathrm{t}_{1 / 2}=42,32$ and $3 \mathrm{~min}$ for $\mathrm{S} / \mathrm{V}=10.0,12.2$ and 34.6, respectively [48].

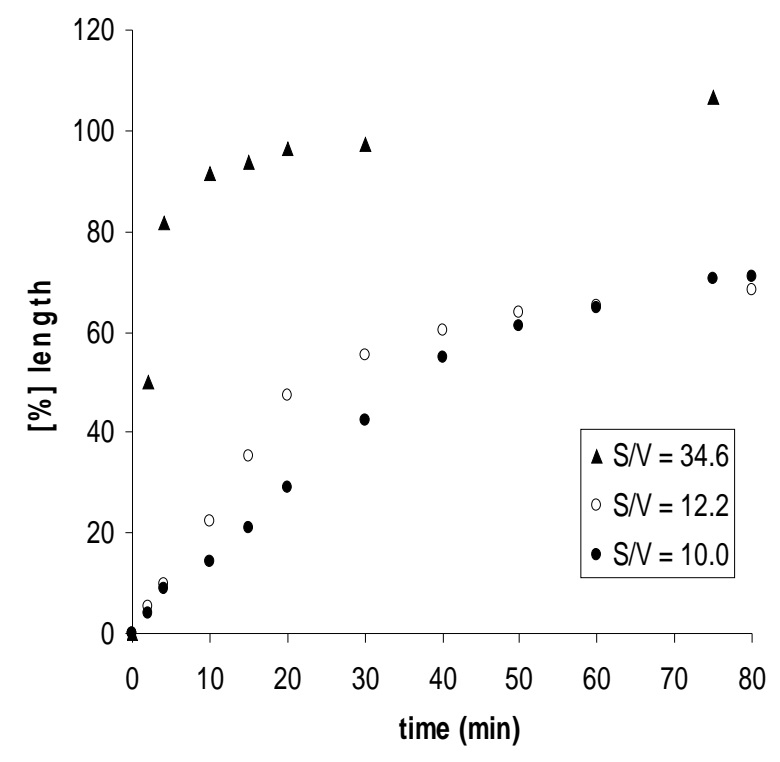

Figure 4. Effector AMP concentration needed for a certain expansion (here $35 \%$ in volume) of polymer $\mathbf{I}$ as a function of the polymer particle size (variable length, with constant width and thickness; in $0.02 \mathrm{M}$ phosphate buffer, $\mathrm{pH}=7.0$ ). Volume expansions of up to $300 \%$ are possible under the working conditions with the smaller particles.

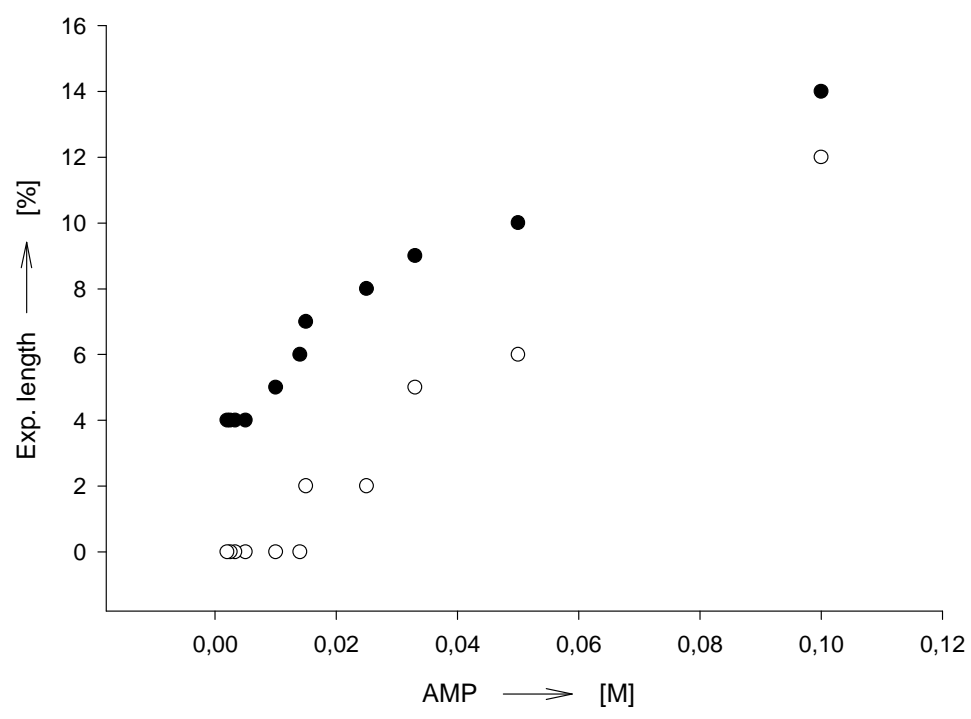


The particle size of a chemomechanical polymer has an important effect on the sensitivity of response to an external chemical signal. It has been mostly overlooked that smaller particles may need a smaller amount of effector for saturation [57]. The possible sensitivity increase with the decrease of a particle volume has been only described in the context of sensor miniaturization [58]. This, however, holds only as long as the affinity of an effector towards the sensing material is so high, that all, or nearly all, effector molecules are absorbed, independent of the external effector concentration. As illustrated in Figure 4 the effector concentration which is required to afford a certain volume change of a chemomechanical polymers can be a function of the sensing particle size [57].

Saturation-type profiles as function of the effector concentration can be expected until all binding sites of a chemomechanical polymer are occupied, unless abrupt phase transitions occur. Figure 5 [39b] illustrates in the case of polymer I that such isotherm-like curves can be observed, unless the cooperativity effects discussed below play a role. The curves exhibit only approximately normal saturation isotherms, but allow one to infer the affinity of an effector towards the polymer. The data is analogous to that used to derive apparent association constants of related host-guest complexes in aqueous solution. Thus, the apparent binding constant K e.g. for AMP under the conditions in Scheme 7 is approximately $20 \mathrm{M}^{-1}$, roughly comparable to $\mathrm{K}$ values reported in homogenous solutions for the interaction of AMP and ethylenediamine-type host compounds.[59] From the first part of the characteristically discontinuous concentration profiles observed when using transition metal ion effectors [60] and the maximum expansions reached there one can estimate affinities which are, as expected, much higher than for AMP. For example, $\mathrm{Cu}$ (II) ions have an apparent $\mathrm{K}$ value around $10^{5}$ to $10^{6} \mathrm{M}^{-1}$. However, the profiles not only depend on the presence of additional salts or buffers, but also show a lag period before swelling begins (Figure 5). In contrast, UV/vis measurements show absorption begins to occur at concentrations which are too low to induce gel expansion. The expansion starts at a concentration at which presumably the effector starts to move inside the gel after initially saturating the surface.

Figure 5. Expansion (length) as function of AMP concentration; polymer I, film size $5.0 \times 2.0 \times 0.4 \mathrm{~mm}, \mathrm{pH} 7.0$. Lower trace $(0)$, in absence of buffer; upper trace $(\bullet)$, in presence of $0.02 \mathrm{M} \mathrm{NaH}_{2} \mathrm{PO}_{4}$ buffer. Schneider, H. J.; Liu, T. J.; Lomadze, N. Dimension changes in a chemomechanical polymer containing ethylenediamine and alkyl functions as selective recognition units. Eur. J. Org. Chem. 2006, 677-692. Copyright Wiley-VCH Verlag GmbH \& Co. [39b].

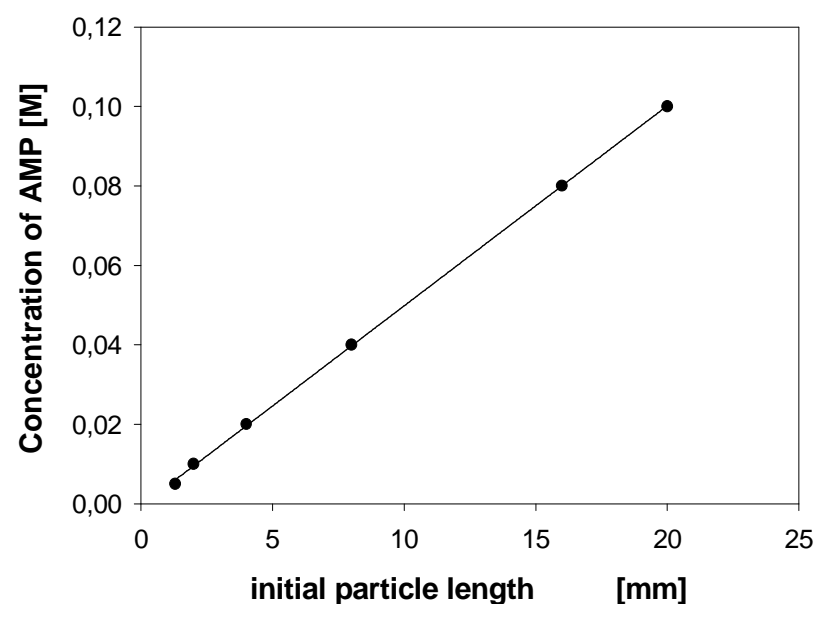




\section{Cooperativity between different effector molecules; logical gate functions}

In supramolecular solution chemistry it has been shown, how two different chemical entities can be necessary for a certain response [61]. For example a fluorescence signal is only emitted (or quenched) from a host-guest complex if the $\mathrm{pH}$ has a certain value, and a second compound is present simultaneously. Such systems are either based on cooperativity between different guest molecules, or on allosteric effects between two or more distinct binding and conformationally coupled sites. As mentioned above, $\mathrm{pH}$-induced swelling of chemomechanical polymers often depends also on, e.g., salt concentrations or rather ionic strength, which may be considered as examples of simple, though rather nonselective, cooperativity. Only recently has it been shown that with a chemomechanical polymer bearing several recognition functions such as $\mathbf{I}$, that a selective response can materialize which is attributable to several effectors [62] (Scheme 6). The cooperativity can be so strong, that a volume change occurs with e.g. peptides only if a certain metal cation is present (see section 8). Such gel-based logical AND gate systems require no spectroscopic detection and transducers, but communicate directly to the outside world.

Scheme 6. Cooperativity effects in a polymer containing two binding sites A and B with two guest molecules $\mathbf{G 1}$ and G2; $\boldsymbol{S}$ : small/tight; $\boldsymbol{M}$ : medium loose; $\mathbf{L}$ : large loose network.

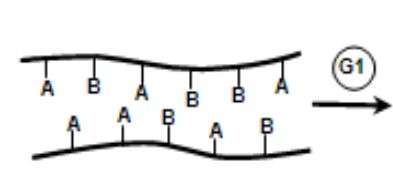

$S$

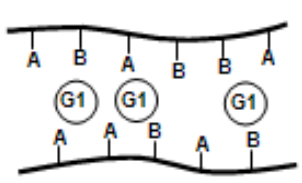

M

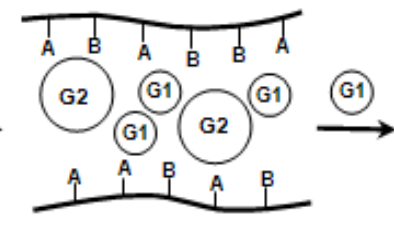

$L$

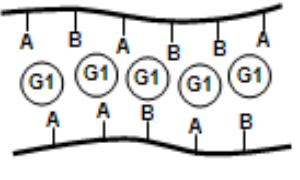

M

The expansion stimulated on the functional polymer I by different effectors depends distinctly on the $\mathrm{pH}$, thus representing an efficient macroscopic AND gate system. Thus, the expansion magnitude induced by the nucleotides UMP and AMP is reversed upon_changing the $\mathrm{pH}$ from 7 to $\mathrm{pH} 11$ (Scheme 7) [39].

Logical AND gates in the sense of positive cooperativity are not only functional due to the influence of $\mathrm{pH}$ but also to different effectors. For example, with polymer I the expansion induced by AMP reaches a distinct maximum only at a certain concentration of phosphate anions as a second effector. [39] With other effectors also negative cooperativity has been observed; e.g. the presence of sodium salts distinctly lowers the expansion induced in polymer I by zinc acetate [60].

The ethylenediamine units in $\mathbf{I}$ allow chelation and selective volume changes with transition metal ions [60,63]; as expected, low $\mathrm{pH}$ values lead to a reversal of the expansions, since the ethylenediamine units become protonated- another manifestation of cooperativity with $\mathrm{pH}$. The critical effector concentration at which the expansion reaches a maximum has been shown to correlate with the size of the polymer particle, for the reasons discussed above in the context of the relation between size and sensitivity. 
Scheme 7. Expansions (in \% volume) triggered by nucleotides UMP and AMP and phosphate $(0.1 \mathrm{M})$ at different $\mathrm{pH}$ values; chemomechanical polymer I [39a].<smiles>O=c1ccn(C2OC(COP(=O)(O)O)C(O)[C@H]2O)c(=O)[nH]1</smiles>

at pH 7 :

at $\mathrm{pH} 11$ :<smiles>Nc1ncnc2c1ncn2C1O[C@H]2O[C@H]1C(O)[C@H]2OP(=O)(O)O</smiles>

75

60<smiles>O=P(O)(O)O</smiles>

$<10$

$<10 \quad$ vol $\%$

\section{Selective response to organic effector molecules}

Relatively large differences in swelling promoted by various organic compounds have been observed with polymers such as I. They can be understood and planned on the basis of interaction mechanisms known from supramolecular chemistry. As indicated in Scheme 2, the ethylendiamine (ene) units allow not only metal chelation and $\mathrm{pH}$-dependent protonation, but also hydrogen bonding as well as $\mathrm{N}^{+}$cation- $\pi$ effects. That the latter play an essential role is clear from the large chemomechanical effects observed only when aryl units are present in the effector molecule: the saturated cyclohexane-carboxylate has, within error, no effect in contrast to the nearly isosteric benzoic acid (Scheme 8) [39a]. That electrostatic attraction, or ion pairing with the cationic $\mathrm{N}^{+}$sites in $\mathbf{I}$ is an additional prerequisite for any size changes of the gel is evidenced by the inactivity of electroneutral compounds. Finally, the alkyl groups introduced into polymer I provide for lipophilic interactions, which vary among the different organic moieties of the effectors. In consequence, not only nucleotides (see Scheme 7) but even structural isomers such as different benzene dicarboxylicacids can be distinguished (Scheme 8).

Scheme 8. Selectivity between different organic effector compounds of polymer I [0.02$0.05 \mathrm{M}$ phosphate buffer; the effects at $\mathrm{pH} 11$ are corrected for difference between $\mathrm{pH} 7$ and $\mathrm{pH} 11$ alone (390 vol \%)] [39a].

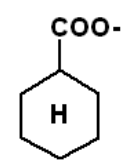

at $\mathrm{pH} 7,1 \mathrm{mM}: \quad<10$<smiles>O=C([O-])c1ccccc1</smiles>

40<smiles>O=C([O-])c1cccc2ccccc12</smiles>

150<smiles>O=C([O-])c1c2ccccc2cc2ccccc12</smiles>

320<smiles>O=C(O)c1ccc(C(=O)O)cc1</smiles><smiles>O=C(O)c1ccccc1C(=O)O</smiles><smiles>O=C(O)c1cccc(C(=O)O)c1</smiles> 
Lipophilic interactions are also responsible for the unique contraction of polymer I upon exposure to ammonium compounds bearing longer alkyl chains, Scheme 9 illustrates the systematic change from the usual expansion to shrinking [39b]. It should be borne in mind, that small expansion differences can be sufficient to switch, e.g., the release of a drug from a suitable container, on or off.

Scheme 9. Dimension changes (volume, in [\%] ) with peralkylammonium hydroxides $\mathrm{R}_{4} \mathrm{NOH}$ (after correction for $\mathrm{pH}$-induced change, $\mathrm{pH} 12.4$ to 12.7 ). Schneider, H. J.; Liu, T. J.; Lomadze, N. Dimension changes in a chemomechanical polymer containing ethylenediamine and alkyl functions as selective recognition units. Copyright Wiley-VCH Verlag GmbH \& Co. [39b].

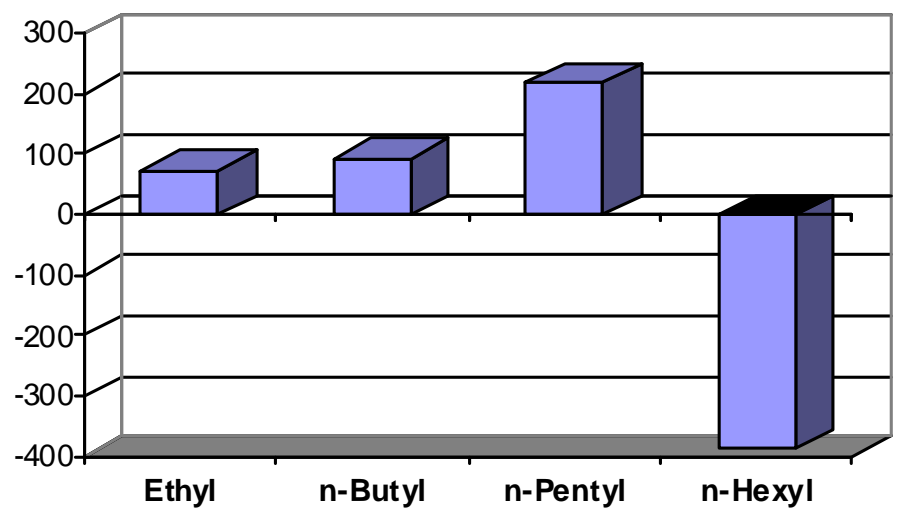

Stacking interactions between aromatic units are an important binding mechanism in supramolecular complexes as well as in nature [64]. The introduction of anthrhyl groups into chitosan II creates large interaction sites for aromatic effectors, although the degree of substitution was low. In the presence of various amino acids one observes expansions which, as expected, increase in magnitude with the lipophilicity of the residues (Scheme 10) [65]. Another van der Waals-type force involves cation- $\pi$ interactions, which contribute to the functioning of chemomechanical polyamine hydrogels, when the nitrogen centers are protonated and aromatic residues are present in the effector compounds.

Scheme 10. Volume expansions [\%] on chitosan-anthrhyl polymer with different aminoacid esters; $\mathrm{pH}$ and salt effects deducted; (pH 5.0; $0.1 \mathrm{M}$ effector) [65].<smiles>COC(=O)C(C)[C@@H](N)[NH3+]</smiles>

1.3<smiles>COC(=O)C(C)[NH3+]</smiles>

1.9<smiles>COC(=O)C([NH3+])Cc1ccccc1</smiles>

17<smiles>COC(=O)[C@H]([NH3+])Cc1c[nH]c2ccccc12</smiles>

31 
Selectivity can also seen in the combined effect of two substrates $\mathbf{A}$ and $\mathbf{B}$ such as e.g. naphthoic acid $\mathbf{A}$ and phenylalanine $\mathbf{B}$, which both lead to contraction of polyethylenimine (PEI) gels. The simultaneous action of $\mathbf{A}$ and $\mathbf{B}$ exceeds that of $\mathbf{A}$ and $\mathbf{B}$ alone by $21 \%$. The results can be explained first by the replacement of the originally present chloride anions by either $\mathbf{A}$ or $\mathbf{B}$, which is supported by cation- $\pi$ interactions with the aromatic residues of $\mathbf{A}$ or $\mathbf{B}$ and the cationic polymer backbone [66]. The N-terminus of the aminoacid can furthermore form salt bridges with the A-carboxylate residue, thus stabilizing the incorporation of both effectors within the gel (Scheme 11). Other effectors such as benzoic or aliphatic acids do not show such positive cooperativity.

Scheme 11. Model for cooperative contraction mechanism. Replacement of chloride by naphthoate $(\mathrm{a} \rightarrow \mathrm{b})$ can lead to cation- $\pi$ interactions and $\mathrm{COO}^{-} \ldots{ }^{+} \mathrm{NH}_{3}$ salt bridges, with concomitant solvation water release. Introduction of second effector aminoacid $(b \rightarrow c)$ : additional $\mathrm{COO}^{-} \ldots{ }^{+} \mathrm{NH}_{3}$ salt bridges, more water release. The relevant non-covalent interactions are indicated as dashed lines. Reprinted with permission from ref. [66] Copyright (2007) American Chemical Society.

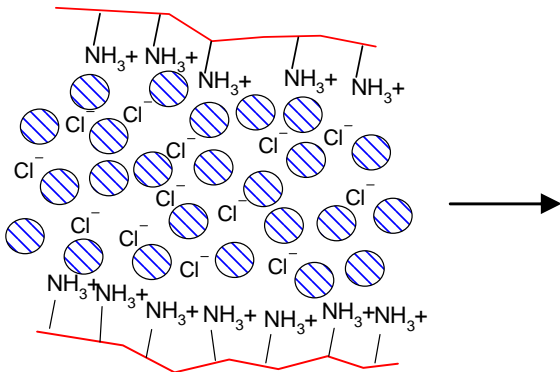

a

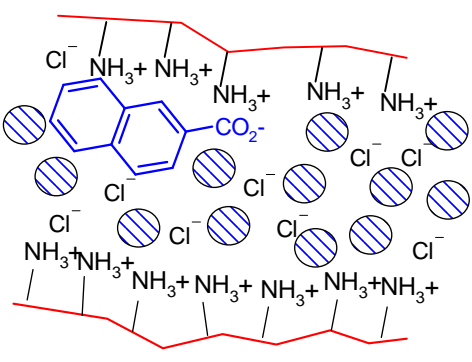

b

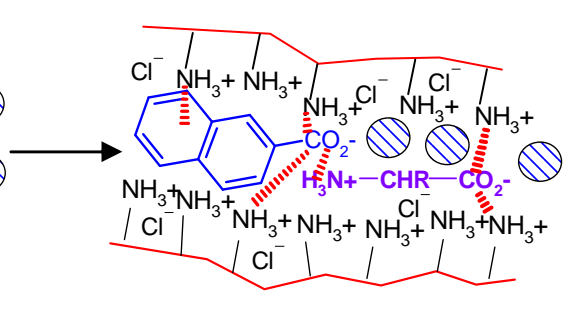

C

Even without introducing specific host functions into polymers one can often observe selective size changes in chemomechanical polymers. Chitosan gels II show expansion differences not only between certain carboxylic acids, but also between basic and non-basic native (unprotected) aminoacids. The underivatisized polyallylamine III, crosslinked for gel-formation, exhibits some interesting selectivity.

Using small angle X-ray scattering (SAXS, Figure 6) it has been shown that incorporation of strongly bound salts such as arylsulfonates leads to ordered structures, with distances between the polymer backbone which increase with the size of the guest molecules [47]. Such effectors lead to weight decreases of $95 \%$; re-swelling is possible by treatment with excess of weaker effectors such as $\mathrm{NaCl}$ which cause only a $40 \%$ weight loss.

The PAH polymer gel III allows one to distinguish even some isomeric compounds (Scheme 12). Generally, ionic crosslinking leads to volume decreases with all kinds of carboxylic acids, with significant differences between natural glucoronic and glucaric acids. Surprisingly, benzoic acids with suitable substituents also promote large contractions similar in size to dicarboxylic acids, presumably as result of stacking interactions between the aryl rings, in analogy to Figure 7 [60]. 
Figure 6. SAXS patterns of collapsed gels derived from polyallylamine III in various aromatic sodium salt solutions $(0.07 \mathrm{M})$. Reprinted with permission from ref. [47]. Copyright (1999) American Chemical Society.

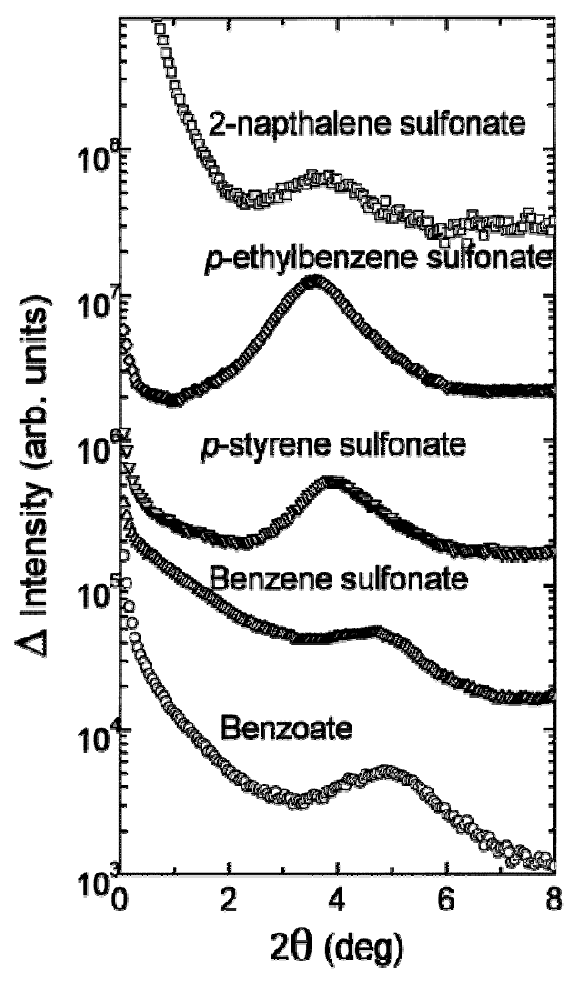

Scheme 12. Volume change of PAH gel III in the presence of different acids effectors at pH 7 [48].
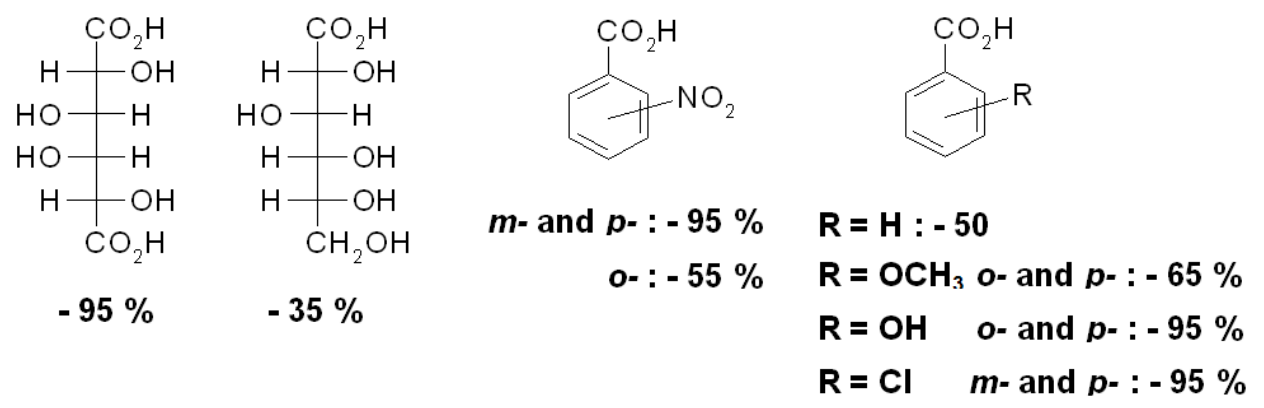

Figure 7 . Model of a polyallylamine III-derived gel with substituted aromatic acids as counterion spacers. [48]

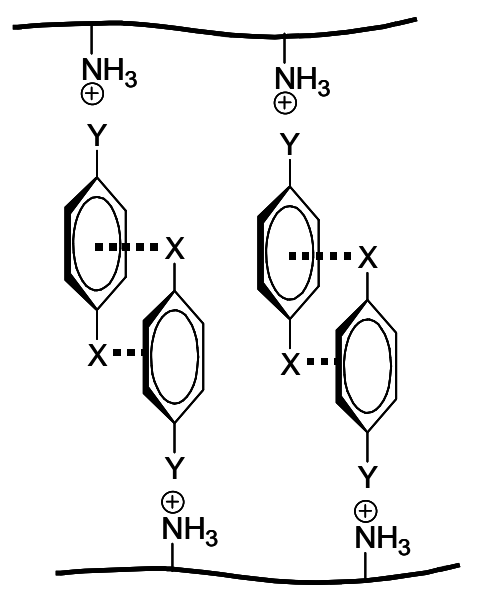

$\mathrm{X}=\mathrm{CH}=\mathrm{CH}_{2}, \mathrm{NO}_{2}$, OH etc.

$\mathrm{Y}=\mathrm{SO}_{3}^{-}, \mathrm{CO}_{2}^{-}$etc. 
Nitro substituents have been shown to interact strongly with other aromatic moieties by dispersive forces, [67] which would explain why the nitrobenzoic acids lead to particularly sizeable contractions as long as the nitro moiety is not proximal to the anionic carboxylate center.

\section{Chiral discrimination}

Size changes triggered selectively by enantiomeric effectors pose one the most interesting projects as it would allow, for the first time, the translation of chiral recognition directly to the outside world. In principle this can be achieved by the presence of optically active components within a chemomechanical polymer. Until now only the influence of chiral effector compounds or constituents on gelation, on the structure of gel materials [68], and on phase or sol-gel transitions [69] has been investigated. The gel derived from natural chitosan contains relatively well-ordered chiral aminoglucose units and is suitable for such applications [70]. In the case of histidine one observes a moderate, yet promising enantioselective difference in swelling, depending on the acid anion with which it is competing, with preference for the $D$-enantiomer over the $L$-form. The differences are 145 $\%$ vs. $120 \%$ in the presence of acetate; to $134 \%$ vs. $123 \%$ in the presence of benzoate, whereas no difference was observed in the presence of chloride [48]. Much larger enantioselectivity is attained with optically active effectors containing several aromatic residues such as dibenzoyltartraric acids (DBTA). In the presence of acetic acid as a cofactor one enantiomer triggers up to a $95 \%$ volume decrease of the chitosan gel, whereas the optical antipode leads to less than a $20 \%$ change, depending on effector concentration (Figure 8).

Figure 8. Volume contraction of the gel II in the presence of acetic acid as cofactor, induced either by (-)- $L$-DBTA (filled circles), or by (+)-D-DBTA (open circle) at $\mathrm{pH} 3.5$; starting volume of gel particle $5 \pm 0.3 \mathrm{~mm}^{3}$. Schneider, H. J.; Kato, K. Direct translation of chiral recognition into mechanical motion. Angew. Chem. 2007, 119, 2748 -2750; Angew. Chem. Int. Ed. Engl. 2007, 46, 2694 -2696. Copyright Wiley-VCH Verlag GmbH $\&$ Co..[70]

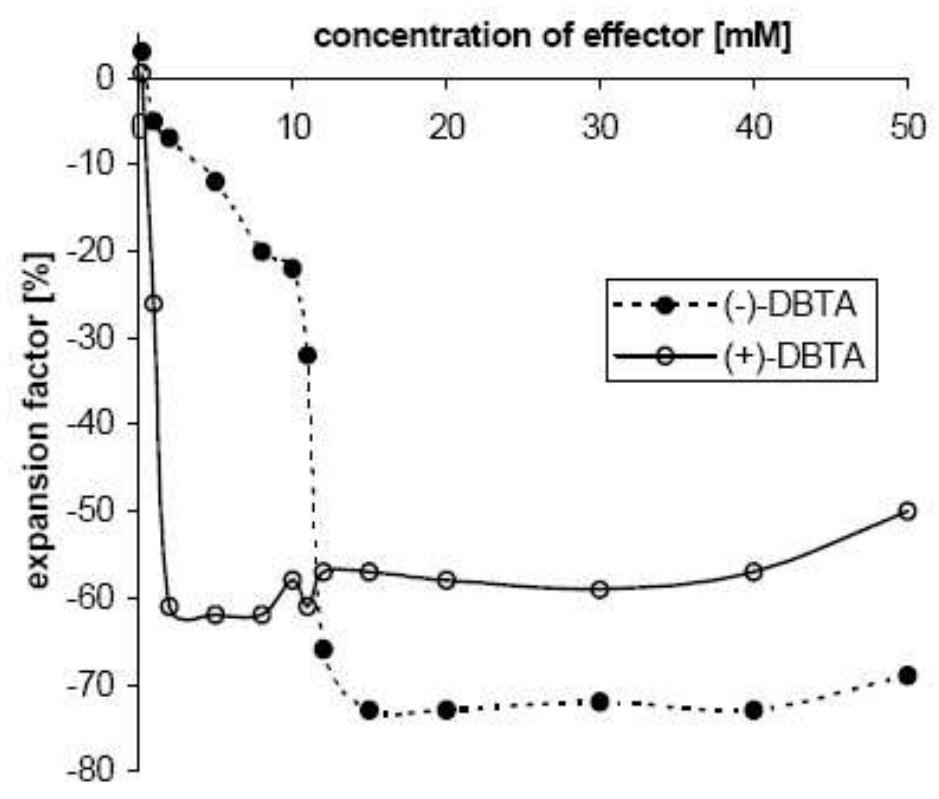


Figure 9. Solid-state ${ }^{1} \mathrm{H}$ CP/MAS NMR spectra of chitosan gels II in the presence of AcOH cofactor, with structure model including signal numbering. (a) The swollen gel itself, (b) the gel treated with $5 \mathrm{mM}$ of (-)-L-DBTA and (c) the gel treated with $5 \mathrm{mM}$ of (+)-D-DBTA. Copyright Wiley-VCH Verlag GmbH \& Co. [70].

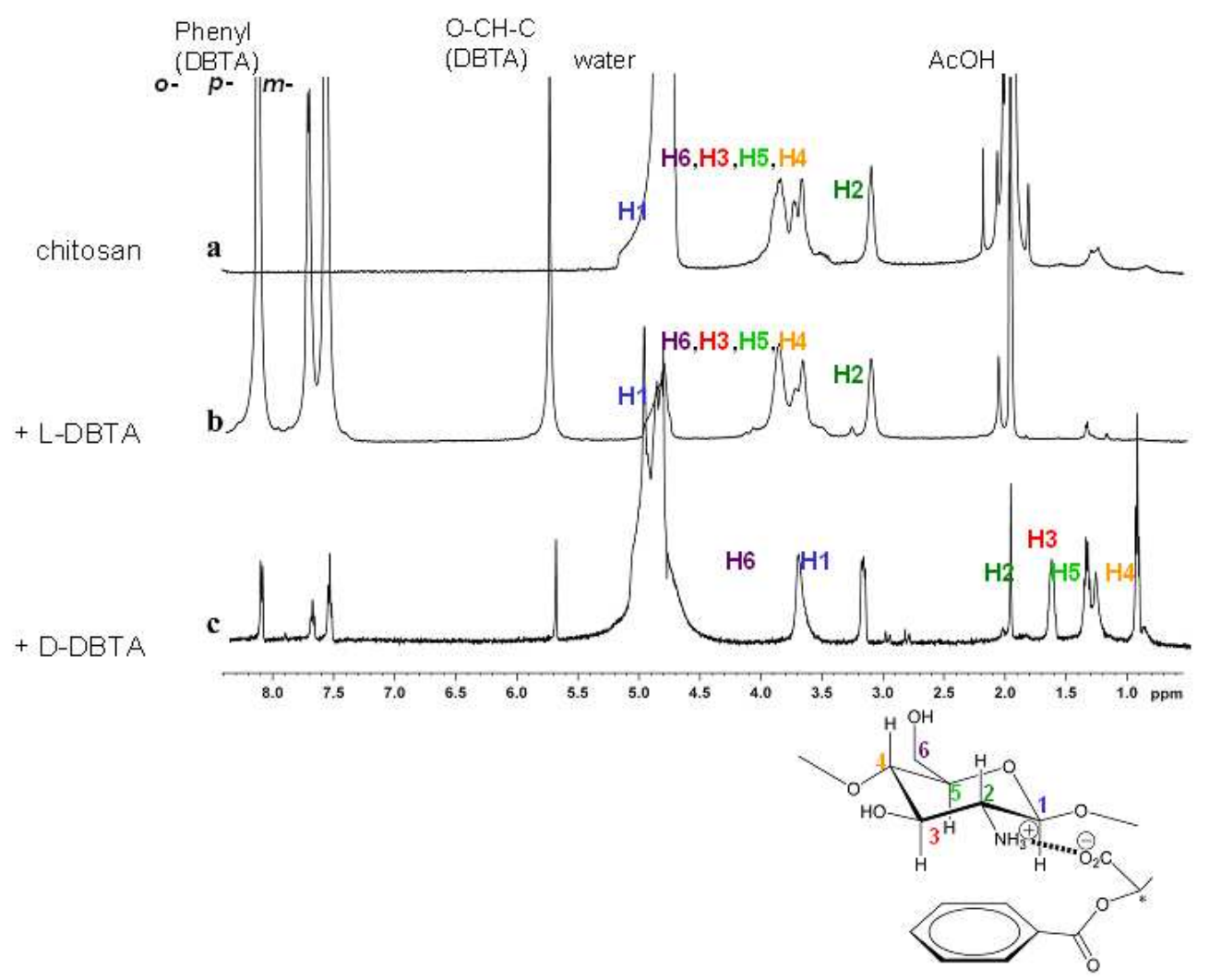

At relatively low concentrations, where the antipode is barely active, the $D$-isomer induces large motions, whereas at higher concentrations the $L$-isomer has larger effects. The concentration profiles can be ascribed to a higher affinity of the $D$-isomer, so that the $L$-antipode is fully bound only at higher concentrations. The contraction is likely due to ionic cross-linking by the dicarboxylic acid DBTA, which can replace the single acetic acid molecules within the gel. In accord with this, solid state ${ }^{1} \mathrm{H}$ MAS NMR spectra of the DBTA-loaded gel (Figure 9) shows after effector loading, the DBTA signals and large upfield shifts of the aminoglucose units of the polymer backbone only in the case of the chemomechanically very active antipode. The shielding observed with the $D$-isomer amounts to up to $2.5 \mathrm{ppm}$, indicating a strong interaction between the DBTA phenyl groups, with a face-to-face orientation between the glucose units and the effector aryl residues. Such a geometry is in line with the shielding by the anisotropy cone of the phenyl rings, and is expected from the well-known cation- $\pi$ interaction with the protonated nitrogen centers of the polymer backbone, supported also by $\mathrm{CH}-\pi$ interactions with the axial glucose hydrogens.

The contraction kinetics for $D$-DBTA show a significantly faster volume change than with the $L$ isomer. Furthermore, the desorption profiles, observed by spectroscopic detection of DBTA liberated from effector-loaded polymer particles exhibit faster release of $L$-DBTA, in line with the smaller affinity of that isomer. The spectroscopically observed desorption kinetics exhibit a two-phase behaviour, indicating an absorption which amounts to more than that allowed by ion pair formation between one aminoglucose unit of the polymer and the effector (2.6 and 2.0 times excess of $L$-DBTA and $D$-DBTA, respectively). This additional physi-sorption is obviously larger for the $L$-isomer; after a 
longer time, however, the desorption for both isomers reaches the concentration calculated for an approximate 1:1 ion pair formation between the gel monomer unit and the effector. Tartraric acid derivatives lacking two phenyl groups show only negligible chemomechanical differences between the optical isomers.

\section{Activation of silent analytes by ternary complex formation/aminoacids and peptides as effectors}

Analytes which interact not directly with supramolecular binding sites of a polymer can be brought into action, if another, strongly interacting effector molecule exhibits strong binding both to the polymer and to the analyte of interest (Scheme 13) [71]. The ethylenediamine units in polymer I allow to bind strongly transition metal ions such as $\mathrm{Cu}^{2+}$, which in turn are known to associate effectively with e.g. aminoacids or peptides; with a chemomechanical polymer this can lead to sizeable volume expansions (Figure 10) [72]. Related co-complexations have been used successfully already for other sensor applications [73]. The additional interaction groups of polymer I (Scheme 13) provide for additional discrimination with the aminoacid side groups, which is visible in swelling differences between different peptides (Scheme 14). With some special chelating agents the expansions reach a record $475 \%$ on top of the swelling produced by the metal ion itself [71]. Removal of the metal cations by decomplexing agents leads to a reversible contraction of the swollen gel as function of the decomplexing agent chelating strength. It should be noted that analytes such as peptides alone lead to no measurable size changes of the gel, which illustrates again with a chemomechanical polymer the unique feature of a macroscopic logical AND gate.

Scheme 13. Ternary complex formation with chemomechanical polymer I: cocomplexation with metal ions.

$$
\begin{aligned}
& \begin{array}{l}
\text { C tertiary site } \\
\text { e.g. peptide }
\end{array} \\
& \text { B secondary site } \\
& \text { e.g. Cu(II) } \\
& \text { A primary site e.g. ene }
\end{aligned}
$$

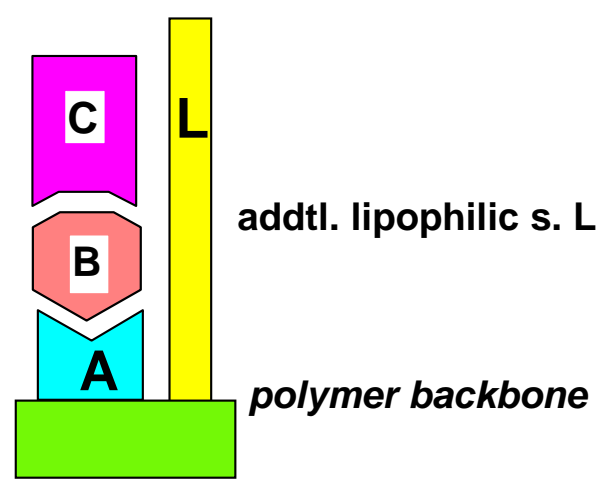

Figure 10. Expansion of a polymer film I piece triggered by co-complexation with $\mathrm{Cu}(\mathrm{OAc})_{2}$ and Gly-Gly, $0.25 \mathrm{mM}$ at $\mathrm{pH} 4.5$.
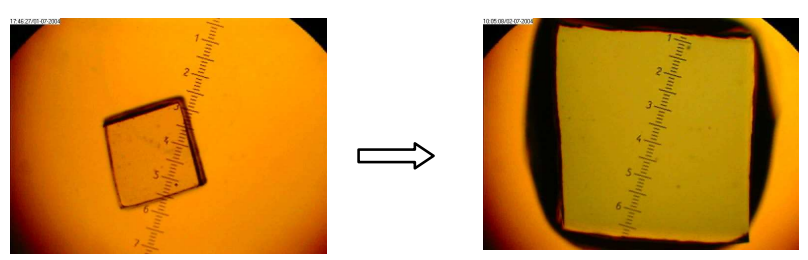
Scheme 14. Examples for expansion (in one dimension) in ternary complexes in case of polymer I; $\mathrm{Cu}(\mathrm{II})$ and Effector $0.25 \mathrm{mM}$; $\mathrm{pH} 4.5$. Net volume expansion: effect of $\mathrm{Cu}^{2+}$ alone deducted [71].

\begin{tabular}{|c|c|c|c|}
\hline \multirow[t]{2}{*}{$\mathrm{H}_{2} \mathrm{~N}$} & \multicolumn{3}{|c|}{$\mathrm{NH}-\stackrel{\mathrm{CH}}{\mathrm{C}}-\mathrm{COOH}^{\mathrm{R}}$} \\
\hline & R1 & $\mathbf{R 2}$ & $\%$ Vol Exp. \\
\hline Ala-Ala & $\mathrm{Me}$ & $\mathrm{Me}$ & 145 \\
\hline Phe-Gly & $\mathrm{CH}_{2} \mathrm{Ph}$ & $\mathrm{H}$ & 225 \\
\hline Trp-Gly & $\mathrm{CH}_{2}$ Indole & $\mathrm{H}$ & 125 \\
\hline Trp-Trp & $\mathrm{CH}_{2}$ Indole & $\mathrm{CH}_{2}$ Indole & 245 \\
\hline
\end{tabular}

\section{Selectivity by covalent interactions: glucose-triggered size changes of chemomechanical polymers.}

Chemosensors functioning via covalent bond formation to an analyte have been recently developed for the detection of amines, alcohols, aldehydes, carbon dioxide, saccharides, thiols, hydrogen sulfite, hydrogen disulfide, cyanide and amino acids [74]. The analogous use of rapid and reversible covalent bond formation to selectively trigger size macroscopic changes in synthetic chemomechanical polymers has, except in the case of glucose binding via boronic acids, received only very limited attention to date. It thus embodies a fertile area for investigation. The glucose-related studies in the area of fully synthetic chemomechanical polymers are driven, in large part, by the significant need for improved non- and minimally-invasive sensing and delivery devices for the management of diabetes. The earliest efforts in this area [75] were moreover motivated by the fact that the biomaterial-based recognition elements such as lectins and enzymes, as previously used in hydrogels, raised concerns of stability, toxicity and undesirable immunogenic responses.

Figure 11. Saccharide-induced hybridization and concomitant polarization changes. When saccharides form cyclic boronates, the Lewis acidity of the boronic acid is enhanced by at least $\sim 2 \mathrm{pKa}$ units, resulting in a solvolysis reaction at boron. Thus, the $\mathrm{sp}^{2}$ hybridized boronic acid is more readily converted to a charged $\mathrm{sp}^{3}$ hybridized anion upon saccharide binding. In most cases, cyclic boronate ester formation occurs with a sugar furanose (rather than the shown pyranose).<smiles>OB(O)[AlH2]</smiles><smiles>OCC1OC(O)C(O)C(O)C1O</smiles><smiles>O[SbH](O)(O)O</smiles><smiles>OCC1OC(O)C(O)C(O)C1O</smiles><smiles>[Y8]B1OC2OC(CO)C(O)C(O)C2O1</smiles><smiles>OCC1OC2O[R](O)([123I-])OC2C(O)C1O</smiles> 
In many respects glucose is an ideal target effector in chemomechanical polymers. The extensive studies of boronic acid-glucose binding in aqueous solution [76] reveal that it is (i) a strong and $(\mathrm{pH}-$ dependent) reversible covalent interaction (Figure 11), (ii) a very effective means to enhance negative charge accumulation on boron, thereby rendering a polymeric gel more hydrophilic and inducing significant degrees of swelling and, (iii) with appropriate stoichiometric control during synthesis, selectively condenses of with two boronic acids [77], to promote macroscopic shrinkage by reversible covalent crosslinking (Figure 12) [78,79].

Figure 12. Schematic of glucose as a chemical cross-linker affording significant and selective shrinkage compared to the other common blood sugars in a fully synthetic chemomecanical hydrogel [79].
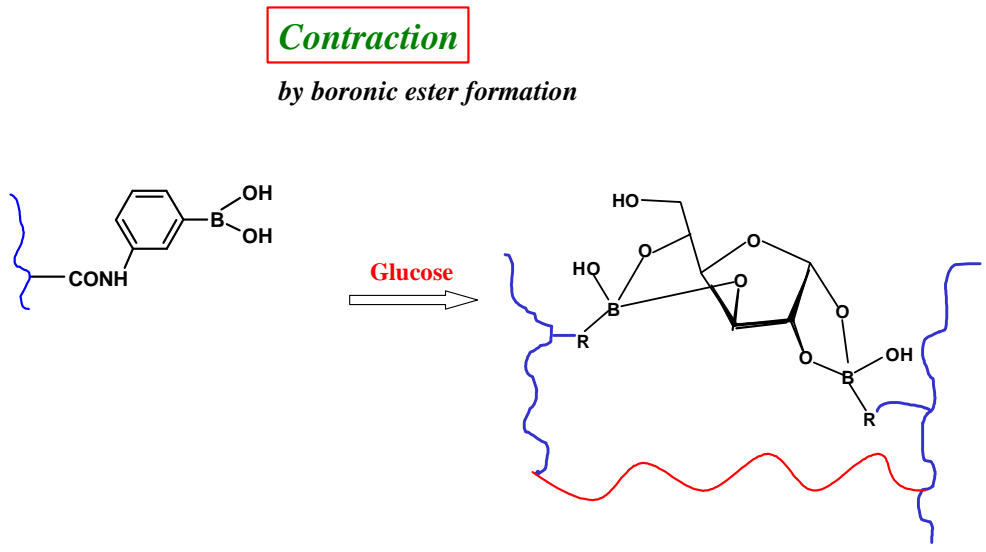

In 1992, Kataoka, Okano and coworkers proposed the fabrication of a potential glucose-regulated insulin delivery system that was based upon glucose binding to a boronic acid-functionalized polymer [75]. A material was synthesized via the free radical polymerization of $N$-vinyl-2-pyrrlidone and macrylamidophenylboronic acid. A polymeric complex was then formed via boronate ester formation to the diol units of poly(vinyl alcohol). Viscosity was shown to markedly increase upon complexation. Upon the addition of glucose as a competitive binding agent, the viscosity decreased significantly while only minor changes were observed upon the addition of tris(hydroxymethyl)aminomethane or 3amino-1,2-propanediol. In the same year Kim et al. also published an analogous boronate-containing gel for insulin delivery based on competitive displacement by glucose of bound boronic acid sites [80].

The scope of the insulin delivery work was extended in 1994 via Kataoka and Okano to the preparation of a material in which gluconated insulin was successfully bound to a similar hydrogel to one used in their prior studies. Derivatized insulin was released upon exposure to glucose in a pulsatile manner at physiological $\mathrm{pH}$. The insulin release response time studies were promising, demonstrating little or no lag time [81]. The next year the same group reported the use of an amine-modified version of the complex that exhibited improved performance. It functioned as a modified insulin release system upon exposure to glucose over $120 \mathrm{~h}$ [82].

A similar material containing both phenylboronic acid and tertiary amine moieties complexed to poly(vinyl alcohol) (PVA) was soon thereafter used as an electrochemical sensor for glucose with a membrane-coated platinum electrode [83]. The polymer complex exhibited enhanced swelling effects proportional to glucose concentration at physiological $\mathrm{pH}$ as glucose displaced the PVA from the 
boronate groups. Swelling of the cast gel membrane upon glucose addition lead to the enhanced diffusion of ions and a concomitant increase in current. The system exhibited an operating range of 0$300 \mathrm{mg} / \mathrm{dL}$ for glucose. Arnold and coworkers much later used a different conductometric approach to detect glucose. It was based on the proton release from water which occurs when boronic acids bind water and boron converts to the $\mathrm{sp}^{3}$ anionic form upon sugar binding, thereby increasing local ionic strength [84]. Though Arnold's sensor was not based on a chemomechanical material it merits mention in this context as it serves as significant proof-of-principle that glucose detection via boronic acids is feasible in a practical and highly challenging matrix such as blood.

Kataoka and coworkers later showed that terpolymer complexes synthesized from m-acrylamidophenylboronic acid, $N, N$-dimethylaminopropylacrylamide (DMAPAA), $N, N$-dimethylacrylamide and PVA could function effectively in their competitive PVA displacement systems. DMAPAA was introduced in the terpolymer to stabilize the phenylborate-polyol complex at physiological $\mathrm{pH}$ [85]. UV difference spectra and control experiments were used to show that the ionization of phenylboronic acid was in fact facilitated in the terpolymer due to favorable boronnitrogen interactions, thereby enhancing complexation degree and glucose responsivity at physiological $\mathrm{pH}$. These results apparently supported evidence that a B-N interaction improved saccharide binding at physiological $\mathrm{pH}$ in many related systems (see also ref. 83).

In 1998 an advance was reported describing dye-labeled insulin release via glucose-induced displacement from a hydrogel synthesized from poly(N-isopropylacrylamide) (PNIPAAm) functionalized with an arylboronic acid [86]. A small amount of $N, N$ '-methylene-bis-acrylamide was used as a cross-linker. A high degree of temperature-dependent swelling was observed in response to added glucose. An increase in glucose concentration from 0 to $5 \mathrm{~g} / \mathrm{L}$ led to a rise in the critical swelling temperature from $22{ }^{\circ} \mathrm{C}$ to $36{ }^{\circ} \mathrm{C}$. Based on estimates derived from the pKa value of the arylboronic acid moieties, the fraction of total (glucose bound plus unbound) boronate anions vs. uncharged boronic acids in the gel was calculated to increase from 0.56 to 0.93 upon addition of $5 \mathrm{~g} / \mathrm{L}$ glucose at $\mathrm{pH}$ 9.0. The increase in borate ions rendered the gel more hydrophilic. Along with a simultaneous increase in ion osmotic pressure due to the counterions, the phase-transition temperature of the gel was reported to thus increase proportional to glucose concentration. The swelling degree due to added glucose was defined as the water content per mass of dried gel [(Wwet - Wdry/Wdry)]. Greater than ten-fold degrees of swelling were observed due to an increase in glucose concentration from 0 to $5 \mathrm{~g} / \mathrm{L}$. Essentially no insulin release occurred below glucose thresholds of $1 \mathrm{~g} / \mathrm{L}$. However, significant insulin release occurred at $3 \mathrm{~g} / \mathrm{L}$ glucose levels. The on-off release of insulin from the gel was readily controlled via raising and lowering the concentration of glucose over six cycles during $4 \mathrm{~h}$.

The use of a different arylboronic acid, with a lower pKa value (7.8), synthesized by Kataoka and coworkers was later shown, in conjunction with the same main chain material used previously (PNIPMAAm), to exhibit glucose-dependent function under near physiological conditions. The new arylborate derivative $\{4$-(1,6-dioxo-2,5-diaza-7-oxamyl) phenylboronic acid, DDOPBA $\}$ maintained a constant a $\mathrm{pKa}$ value irrespective of microenvironment effects ascribed to temperature and associated changes in the polymer hydration state [87].

In 2004, a report of a related system, incorporating a methacrylate-derived third comonomer, exhibited glucose-induced continuous volume changes in the range of normoglycemic (normal blood 
glucose) levels. The authors proposed that this material potentially could be the basis of a selfregulated, insulin-delivery system which could change release properties at normoglycemic levels [88].

The same year, Kataoka and co-workers also reported the fabrication of a polymer gel bead several hundred micrometers in diameter which used 3-acrylamidophenylboronic acid as a monomer and binding agent [89]. Glucose-induced shrinking was accompanied by the formation of a skin layer on the gel surface followed by significant structural changes. It was proposed that such a sub-millimeter scale gel bead with a distinctive skin layer could serve as a chemical valve for controlled solute release.

While much of the work on boronic acid-bearing chemomechanical polymers for use in glucose detection from 1992-2004 was reported by the Kataoka group, Shinkai and coworkers were pioneering work on boronic acid-based organic gelators [90]. Numerous boronic acid-appended and structures were fabricated and evaluated for sugar-induced gelation, membrane formation and related macro structural transitions. In the context of this review, two systems which functioned as fully synthetic boronic acid chemomechanical polymers exhibiting sugar-induced volume changes are noteworthy, though not designed specifically for glucose detection.

In the initial case reported in 1999, adenosine monophosphate (AMP) was imprinted on a quartz crystal microbalance (QCM) resonator surface [91]. Boronic acids were among the initial binding units incorporated into the first molecularly imprinted polymers (MIPs). Polymer adsorption (polycations and polyanion-containing boronic acids) on a thiol-modified resonator gold electrode in the presence of AMP afforded a swollen gel layer that contained an excess of positive charge upon removal of the AMP. This was attributed to the binding of AMP to boron which induced excess polycation deposition. The QCM was responsive to added AMP which induced a mass decrease and shrinking of the gel layer.

The following year, Shinkai and coworkers prepared hydrogels via free radical polymerization of a boronic acid monomer, a crosslinker, and also a cationic monomer [92]. The hydrogels bound nucleotides such as AMP and ATP via the cooperative binding of (i) the boronic acid to the cis diol of the ribose moiety and (ii) electrostatic interactions between the cationic group of the polymer and the analyte phosphate group. Binding in aqueous solution caused swelling and deswelling of the hydrogels. In the case of a cation rich gel, a "charge inversion" effect was observed upon increasing AMP or ATP concentration. The attainment of the neutral state caused gel shrinkage. Controlled nucleotide-induced swelling and deswelling were readily monitored with a QCM resonator.

In 2001 Willner and co-workers reported the synthesis of a m-acrylamidophenylboronic acidacrylamide copolymer via electropolymerization on gold -surfaces such as Au-electrodes, Au-quartz crystals and Au-glass slides [93]. The addition of glucose to the copolymer film led to swelling of the polymer. Faradaic impedance spectroscopy, chronopotentiometry, surface plasmon resonance spectroscopy (SPR), and microgravimetric quartz-crystal-microbalance measurements (QCM) were all used to quantify the swelling and shrinkage of the polymer film. This study showed that a wide variety of physical methods could be used to precisely study glucose-induced dynamics in boronic acid-based chemomechanical polymers.

The same year Grimes and coworkers described the fabrication of a wireless, passive magnetismbased glucose sensor to overcome the limitation of direct wire connections needed for amperometric glucose measurements [94]. The use of remote magnetism-based devices was proposed by the authors to render the in vivo glucose monitoring more practical. A PVA polymer was complexed to a co- 
polymer synthesized from $N, N$-dimethylacrylamide, butylmethacrylate, $N$-[3-(dimethylamino) propyl] acrylamide and 3-methacrylamidophenylboronic acid. The mechanism of glucose-induced swelling was thus analogous to that described above as used by Kataoka, involving competitive displacement of PVA hydroxyls from boron by glucose. In the sensor designed by Grimes four triangularly shaped magnetically soft thin film elements were attached to the synthetic polymer. The swelling induced by glucose caused the magnetostatic coupling between the magnetic sensor elements to decrease, resulting in a measurable lower voltage spike amplitude.

In ensuing years several glucose-responsive chemomechanical polymers exhibiting interesting optical responses were described. One type of material that has generated a great deal of interest for point-of-care and contact lens applications was first described by Asher and coworkers in 2003 [95]. They incorporated a crystalline colloidal array (CCA) into a polyacrylamide hydrogel bearing pendant boronic acids. PCCA architectures consist of periodic crystalline lattices of polystyrene microspheres incorporated in hydrogel films. They are highly colored and serve as diffraction gratings.

The polymerized crystalline colloidal array (PCCA) diffracted visible light as a function of changes in the hydrogel volume expansion induced by sugar-boronate complexation in low ionic strength solutions. In 2004 Braun et al. reported the synthesis of a glucose-sensitive inverse opal hydrogel via the photopolymerization of 2-hydroxyethyl methacrylate and 3-acrylamidophenylboronic acid within a dried poly(styrene) colloidal crystal template, followed by template removal [96]. Glucose addition resulted in the swelling of the hydrogel, monitored by shifts in the optical diffraction wavelength. The material responded to glucose at physiological concentrations and ionic strength. The rate of diffraction shift matched well with diffusion-limited kinetics. The ability to detect glucose-induced diffraction at higher ionic strengths than Asher's previously reported PCCA material was ascribed to a higher concentration of binding groups and a denser hydrogel. The attainment of these latter structural features was ascribed to advantages inherent in the inverse opal synthesis technique.

Asher and coworkers also created a more complex PCCA system which functioned at higher ionic strength via the incorporation of 4-amino-3-fluorophenylboronic acid, along with polyethylene glycol (PEG) functionality [78]. Interestingly, at low glucose concentration $(8-10 \mathrm{mM})$ a blue shift was observed and was ascribed to the well-known ability of a single glucose molecule to bind in a bisdentate manner to two arylboronic acids. A red shift, ascribed to gel expansion and monodentate glucose binding was observed when glucose was present in concentrations of $20 \mathrm{mM}$. Glucose is distinctive in its ability to bind two boronic acid moieties. This material was selective for glucose over other common sugars such as galactose, mannose, and fructose, and functioned successfully at physiological $\mathrm{pH}$. Analogous pegylated polymers based on 4-amino-3-fluorophenylboronic acid and also 4-carboxy-3-fluorophenylboronic acid facilitated glucose sensing in synthetic tear solution at physiologically relevant levels of glucose found in tear fluid.

More recently PCCA boronic acid sensing materials were tailored to achieve rapid-response kinetics by controlling elasticity and the hydrophilic-hydrophobic balance of the hydrogel [97]. The more hydrophobic hydrogel was obtained via copolymerization of n-hexylacrylate into an acrylamidebisacrylamide hydrogel. The sensor response to the average glucose concentrations found in blood (5 $\mathrm{mM}$ ) was less than $90 \mathrm{~s}$ and less than $300 \mathrm{~s}$ to the average glucose concentrations found in human tear fluid $(0.15 \mathrm{mM})$. 
Lowe and coworkers also have reported the design and use of related holographic sensors for monitoring glucose [98]. The sensors were created from hydrogel films containing arylboronic acids, and utilized a diffusion method coupled to laser light exposure to afford reflection holograms. The hologram diffraction wavelength tracked the swelling of the hydrogel film due to the presence of glucose. The holographic method was next applied successfully in the detection of real-time changes in bacterial cell metabolism [99].

Hydrogels were investigated for selectivity enhancement for glucose to diminish significant lactate interference [100]. One successful system employed high concentrations of 3-acrylamidophenylboronic acid (3-APB). Another was based on a different boronic acid, 2-acrylamido-5-fluorophenylboronic acid (5-F-2-MAPB). Both hydrogels afforded increased selectivity for glucose over lactate at physiological $\mathrm{pH}$ and ionic strength. Recently, the Lowe group also synthesized 2-acrylamidophenylboronate (2APB). Extensive structure studies on 2-APB and its complexes revealed that it adopts a zwitterionic tetrahedral form at physiological $\mathrm{pH}$ and binds glucose selectively over lactate both in the holographic sensor format and as a monomeric species in solution [101].

Our group recently reported a new boronic acid-based hydrogel which afforded unique, readily seen glucose-promoted, reversible size changes in a difficult matrix, human blood plasma [79]. The study was also unique in that flexible supramolecular binding sites were easily introduced into pre-existing polymer (PMMA) polymer networks in such a manner as to promote selective, easily tunable macroscopic size changes. By readily changing the modifier groups the hydrogel could either shrink or expand in the presence of glucose. It could exhibit high glucose selectivity and little or no response to the other common blood sugars over a range of physiologically-relevant hypo- and hyperglycemic levels. In contrast to most other systems, these hydrogels respond to heightened glucose levels via volume contraction and not expansion in challenging matrices, thus potentially allowing the fabrication of distinctive actuators or microvalves [102] for drug delivery applications.

Figure 13. Depiction of the apparent mechanism of glucose-induced water expulsion from a functional hydrogel synthesized via introducing flexible binding sites into preexisting polymer(PMMA) polymer networks, in such a manner as to promote tunable macroscopic contraction via inducing bisdentate glucose binding as described in Figure 12 [79].

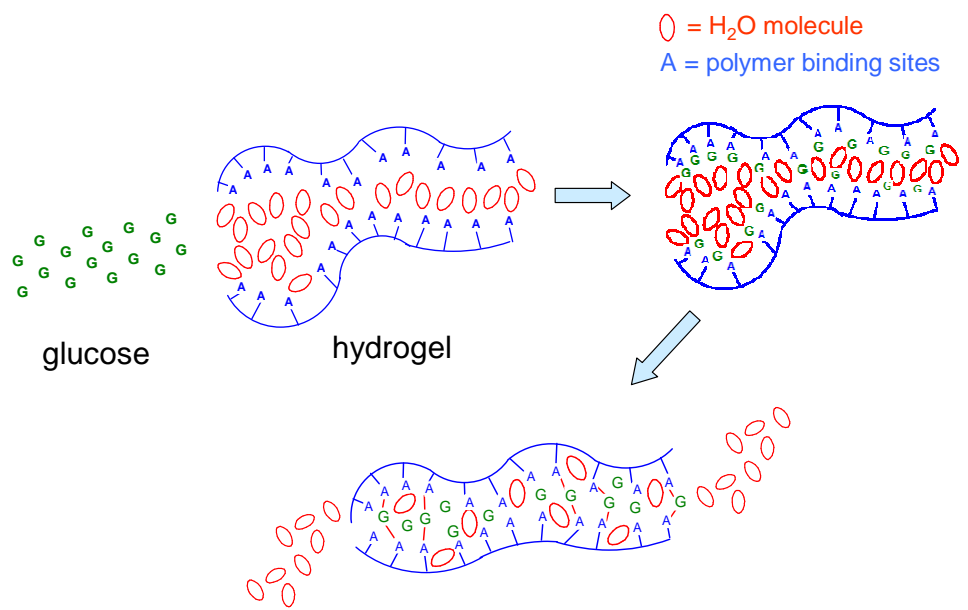

Water is evacuated due to polymer crosslinking with glucose resulting in contraction 
Figure 14. Left: selectivity for glucose over the other most abundant blood sugars, glucose and galactose, can be attained via stoichiometric control over the binding sites introduced into PMMA as described in reference 79. Each of the three sugars are at 0.005 $\mathrm{M}$ concentrations, approximating normal blood glucose levels and $c a$. 100-fold excesses of fructose and galactose. Right: Time-dependent study of polymer contraction in response to $0.005 \mathrm{M}$ glucose added to human blood plasma. The hydrogel also displayed contraction factor degrees that were proportional to glucose concentrations spanning hypo-to hyperglycemic ranges. Samoei, G. K.; Wang, W. H.; Escobedo, J. O.; Xu, X.; Schneider, H.-J.; Cook, R. L; Strongin, R. M. A chemomechanical polymer that functions in blood plasma with high glucose selectivity. Angew. Chem., Int. Ed. Engl. 2006, 45, 5319-5322. Copyright Wiley-VCH Verlag GmbH \& Co. [79].
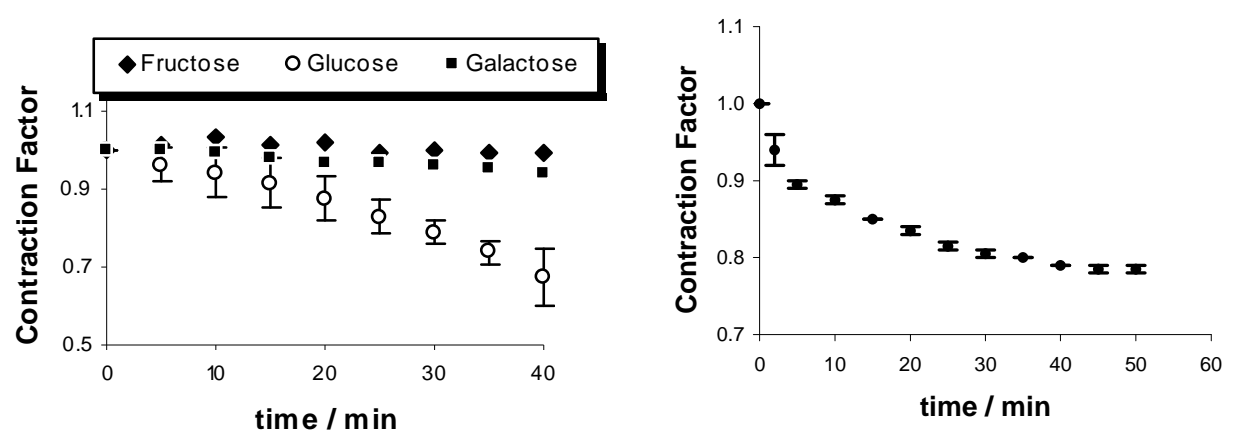

\section{Conclusions}

Supramolecular chemistry has already reached stage, in which for practically any analyte a suitable receptor is known. While this strategy is well developed for solution, the use of such supramolecular binding sits in chemomechanical polymers has been just starting. The implementation of suitable receptor units and the necessary flexibility of corresponding responsive gels provides many challenges for the future. On the other hand, logical gate functions can relatively easily realized with materials responding only if different effector compounds are present within a narrow concentration range, and a macroscopic on/off switch is possible even when smaller size change differences are brought about by different effector molecules.

Great progress has been made in the past 15 years in the design and study of glucose-responsive boronic acid-based chemomechanical hydrogels. Many current challenges remain before a selfregulated insulin-delivery system can be used in a patient. Depending on the material, these include controlling unwanted interactions of a deliverable drug with the polymer [103], response time, biocompatibility, calibration, and robustness. Importantly, studies with other hydrogels as intelligent materials have shown (see section 5), how the speed of response can be enhanced significantly by enlarging the surface to volume ratio of the chemomechanical hydrogel particles, whereas the sensitivity is increased dramatically by downsizing the polymer particles. 


\section{References and Notes}

1. a) Lehn, J.-M. Supramol. Chem. Concepts and Perspectives, VCH: Weinheim, 1995; b) Beer, P.D.; Gale, P. A.; Smith, D. K. Supramol. Chem., Oxford University Press: New York, 1999; c) Schneider, H. -J.; Yatsimirski, A. Principles and Methods in Supra-molecular Chemistry, Wiley: Chichester, 2000; d) Steed, J. W.; Atwood, J. L.; Supramol. Chem., Wiley: New York, 2000; e) Functional Synthetic Receptors Schrader, T.; Hamilton, A. D., Eds.; Wiley-VCH: Weinheim, Germany, 2005.

2. a) Osada, O.; Rossi, D. E., Eds. Polymer Sensors and Actuators; Springer: Berlin, 1999; b) Dai, L. Intelligent Macromolecules for Smart Devices; Springer: London, 2004.

3. a) Dinh, S.M.; P. Liu, P., Eds. Advances in controlled drug delivery: science, technology, and products; An American Chemical Society Publication, Washington, D.C. 2003; b) Hsiue, G.-H.; Okano, T.; Kim, U. Y.; Sung, H-W.; Yui, N.; Park, K. D. Eds. Advances in Biomaterials and Drug Delivery Systems; Princeton International Publishing: Taipei 2002; c) D. T. Eddington and D. J. Beebe, Flow control with hydrogels. Adv. Drug Delivery Rev., 2004, 56, 199-210. Schmaljohann, D. Thermo- and pH-responsive polymers in drug delivery. Adv. Drug Deliv. Rev. 2006, 58, 1655-1670.

4. a) Kaneko, D.; Gong, J. P.; Osada, Y. Polymer gels as soft and wet chemomechanical systems an approach to artificial muscles. J. Mater. Chem. 2002, 12, 2169-2177; b) Shahinpoor, M. Ionic polymer-conductor composites as biomimetic sensors, robotic actuators and artificial muscles - a review. Electrochim. Acta 2003, 48, 2343-2353. Mirfakhrai, T.; Madden, J. D. W.; Baughman, R. H. Polymer artificial muscles. Materials Today 2007, 10, 30-38, Bar-Cohen, Y. Biomimetics using electroactive polymers (EAP) as artificial muscles - A review Adv. Mater. 2006, 38, 3-9; Peppas, N. A.; Hilt, J. Z.; Khademhosseini, A.; Langer, R. Hydrogels in biology and medicine: From molecular principles to bionanotechnology. Adv. Mat.2006, 18, 1345-1360.

5. a) Osada, Y.; Okuzaki, H.; Hori, H. A Polymer Gel with Electrically Driven Motility. Nature 1992, 355, 242-244; b) Osada, Y.; Okuzaki, H.; Gong, J. P. Electro-driven gel actuators. Trends Polymer Sci. (Cambridge, UK) 1994, 2, 61-66; c) Ren, A.; Dalton, L. R. Electroactive polymers including non-linear optical polymers. Curr. Opin. Colloid Interface Sci.1999, 4, 165-171.

6. Shahinpoor, M.; Kim, K. J. Novel ionic polymer-metal composites equipped with physically loaded particulate electrodes as biomimetic sensors, actuators and artificial muscles. Sens. Actuators, A 2002, 96, 125-132.

7. Cortes, M. T.; Moreno, J. C. Artificial muscles based on conducting polymers. e-Polymers 2003, Art.no. 041, 1-42.

8. a) Suzuki, A.; Tanaka, T. Phase-Transition in Polymer Gels Induced by Visible-Light. Nature 1990, 346, 345-347 b) Seki, T.; Takahiro; K.; Kojima; J.; Ichimura, K. Light-Driven Dot Films Consisting of Single Polymer Chain J. Phys. Chem. B 1999, 103, 10338-10340; c) Frkanec, L.; Jokic, M.; Makarevic, J.; Wolsperger, K.; Zinic, M. Bis(PheOH) maleic acid amide-fumaric acid amide photoizomerization induces microsphere-to-gel fiber morphological transition: The photoinduced gelation system. J. Am. Chem. Soc. 2002, 124, 9716-9717, and references cited therein. 
9. a) Bromberg, L.; Temchenko, M.; Hatton, T. A. Dually responsive microgels from polyethermodified poly(acrylic acid): Swelling and drug loading. Langmuir 2002, 18, 4944-4952; b) deGennes, P. G.; Hebert, M.; Kant, R. Artificial muscles based on nematic gels. Macromol. Symp. 1997, 113, 39-49; c) Arndt, K. F.; Schmidt, T.; Reichelt, R. Thermo-sensitive poly(methyl vinyl ether) micro-gel formed by high energy radiation. Polymer 2001, 42, 6785-6791; d) RuelGariepy, E.; Chenite, A.; Chaput, C.; Guirguis, S.; Leroux, J. C. Characterization of thermosensitive chitosan gels for the sustained delivery of drugs. Int. J. Pharm. 2000, 203, 8998; e) Kiyonaka, S.; Sugiyasu, K.; Shinkai, S.; Hamachi, I. First thermally responsive supramolecular polymer based on glycosylated amino acid. J. Am. Chem. Soc. 2002, 124, 1095410955; f) Kobayashi, J.; Kikuchi, A.; Sakai, K.; Okano, T. Cross-Linked Thermoresponsive Anionic Polymer-Grafted Surfaces To Separate Bioactive Basic Peptides. Anal. Chem. 2003, 75, 3244-3249.

10. a) Hoffman, A.S.; Stayton, P.S.; Bulmus, V.; Chen, G.; Chen, J.; Cheung, C.; Chilkoti, A.; Ding, Z.; Dong, L.; Fong, R.; Lackey, C.A.; Long, C.J.; Miura, M.; Morris, J.E.; Murthy, N.; Nabeshima, Y.; Park, T.G.; Press, O.W.; Shimoboji, T.; Shoemaker, S.; Yang, H.J.; Monji, N.; Nowinski, R.C.; Cole, C.A.; Priest, J.H.; Harris, J.M.; Nakamae, K.; Nishino, T.; Miyata, T. Really smart bioconjugates of smart polymers and receptor proteins. J. Biomed. Mater. Res. 2000, 52, 577-586; b) Otero T.F.; Villanueva S.; Cortes M.T.; Cheng S.A.; Vazquez A.; Boyano I.; Alonso D.; Camargo R. Electrochemistry and conducting polymers: soft, wet, multifunctional and biomimetic materials. Synth. Met. 2001, 119, 419-420.

11. Tanaka, T. Collapse of Gels and Critical Endpoint. Phys. Rev. Lett. 1978, 40, 820-823.

12. Ito K.; Chuang J.; Alvarez-Lorenzo C.; Watanabe T.; Ando N.; Grosberg A.Y.. Multiple point adsorption in a heteropolymer gel and the Tanaka approach to imprinting: experiment and theory. Prog. Polym. Sci. 2003, 28, 1489-1515; b) Responsive Gels. Volume Transitions II; Dusek, K., Ed.; Springer, Berlin, 1993.

13. a) Annaka, M.; Tanaka, T. Multiple Phases of Protein Gels. Physica A 1994, 204, 40-46; b) Annaka, M.; Tanaka, T. Multiple Phases of Polymer Gels. Nature 1992, 355, 430-432.

14. Wulff, G. Enzyme-like catalysis by molecularly imprinted polymers. Chem. Rev. 2002, 102, 127. Mosbach, K. Molecular Imprinting. Trends Biochem.Sci. 1994, 19, 9-14. Alexander, C.; Davidson, L.; Hayes, W. Imprinted polymers: artificial molecular recognition materials with applications in synthesis and catalysis. Tetrahedron 2003, 59, 2025-2057.

15. Bartsch, R. A.; Maeda, M., Molecular and Ionic Recognition with Imprinted Polymers; ACS Symp. Ser. 703, 1998; pp 338.. Byrne, M. E.; Oral, E.; Hilt, J. Z.; Peppas, N. A. Networks for recognition of biomolecules: Molecular imprinting and micropatterning poly(ethylene glycol)containing films. Polym. Adv. Technol. 2002, 13, 798-816. Asanuma, H.; Hishiya, T.; Komiyama, M. Tailor-made receptors by molecular imprinting. Adv. Mater. 2000, 12, 10191030.

16. Alvarez-Lorenzo, C.; Guney, O.; Oya, T.; Sakai, Y.; Kobayashi, M.; Enoki, T.; Takeoka, Y.; Ishibashi, T.; Kuroda, K.; Tanaka, K.; Wang, G.; Grosberg, A.Yu.; Masamune, S.; and Tanaka, T. Polymer gels that memorize elements of molecular conformation. Macromolecules 2000, 33, 8693-8697. Moritani, T.; Alvarez-Lorenzo, C. Conformational imprinting effect on stimuli-sensitive gels made with an "Imprinter" monomer. Macromolecules 2001, 34, 7796-7803. 
17. Watanabe, M.; Akahoshi, T.; Tabata, Y.; Nakayama, D. Molecular specific swelling change of hydrogels in accordance with the concentration of guest molecules. J. Am. Chem. Soc. 1998, 120, 5577-5578.

18. See ref. 4; by pH alone: Oral, E.; Peppas, N. A. Responsive and recognitive hydrogels using star polymers. J. Biomed. Mater. Res. Part A 2004, 68A, 439-447 (involving also glucose imprinting). Robinson, D. N.; Peppas, N. A. Preparation and characterization of pH-responsive poly(methacrylic acid-g-ethylene glycol) nanospheres. Macromolecules 2002, 35, 3668-3674. Kaneko, M.; Fukui, M.; Takashima, W.; Kaneto, K. Electrolyte and strain dependences of chemomechanical deformation of polyaniline film. Synth. Met. 1997, 84, 795-796. Suzuki, K.; Yumura, T.; Tanaka, Y.; Akashi, M. pH-responsive model drug release from silicapoly(methacrylic acid) interpenetrating gel hybrids. J. Bioact. Compat. Polym. 2001, 16, 409418. Roux, E.; Lafleur, M.; Lataste, E.; Moreau, P.; Leroux, J. C. On the characterization of pHsensitive liposome/polymer complexes. Biomacromolecules 2003, 4, 240-248. and references cited therein.

19. Brannonpeppas, L.; Peppas, N. A. Equilibrium Swelling Behavior of Ph-Sensitive Hydrogels. Chem. Engin. Sci. 1991, 46, 715-722. Siegel, R. A.; Firestone, B. A. Ph-Dependent Equilibrium Swelling Properties of Hydrophobic Poly-Electrolyte Copolymer Gels. Macromolecules 1988, 21, 3254-3259. and references cited therein.

20. Kuhn, W.; Hargitay, B.; Katchalsky, A.; Eisenberg, H. Reversible Dilation and Contraction by Changing the State of Ionization of High-Polymer Acid Networks. Nature 1950, 165, 514-516.

21. Shahinpoor, M. Microelectro-mechanics of ionic polymeric gels as synthetic robotic muscles. Proc. SPIE-Intern. Soc. Opt. Eng., 1994, 2189, 265-274; see also Shahinpoor, M. Ionic polymerconductor composites as biomimetic sensors, robotic actuators and artificial muscles - a review. Electrochim. Acta 2003, 48, 2343-2353.

22. Leading references on chemomechanical polymers as pH-sensitive sensors: Zhang, L.; Seitz, W. R. A pH sensor based on force generated by $\mathrm{pH}$-dependent polymer swelling. Anal. Bioanal. Chem. 2002, 373, 555-559. Rooney, M. T. V.; Seitz, W. R. An optically sensitive membrane for pH based on swellable polymer microspheres in a hydrogel. Anal. Commun. 1999, 36, 267-270.

23. G.R. Mahdavina, M.J. Zohuriaan-Mehr, A. Pourjavadi, Polym. Adv. Technol., 2004, 15, 173.

24. Nam, K.; Watanabe, J.; Ishihara, K. Network structure of spontaneously forming physically cross-link hydrogel composed of two-water soluble phospholipid polymers. Polymer 2005, 46, 4704-4713.

25. Hirotsu, S.; Hirokawa, Y.; Tanaka, T. Volume-Phase Transitions of Ionized N-Isopropylacrylamide Gels. J. Chem. Phys. 1987, 87, 1392-1395.

26. Podual, K.; Peppas, N. A. Relaxational behavior and swelling-pH master curves of poly[(diethylaminoethyl methacrylate)-graft-(ethylene glycol)] hydrogels. Polym. Int. 2005, 54, 581-593.

27. Eichenbaum, G. M.; Kiser, P. F.; Dobrynin, A. V.; Simon, S. A.; Needham, D. Investigation of the swelling response and loading of ionic microgels with drugs and proteins: The dependence on cross-link density. Macromolecules 1999, 32, 4867-4878.

28. Iversen, C.; Kjoniksen, A. L.; Nystrom, B.; Nakken, T.; Palmgren, O.; Tande, T. Linear and nonlinear rheological responses in aqueous systems of hydrophobically modified chitosan and its 
unmodified analogue. Polym. Bull. 1997, 39, 747-754. Hamdine, M.; Heuzey, M. C.; Begin, A. Effect of organic and inorganic acids on concentrated chitosan solutions and gels. Int. J. Biol. Macromol. 2005, 37, 134-142. Montembault, A.; Viton, C.; Domard, A. Rheometric study of the gelation of chitosan in aqueous solution without cross-linking agent. Biomacromolecules 2005, 6, 653-662.

29. Kam, H. M.; Khor, E.; Lim, L. Y. Storage of partially deacetylated chitosan films. J. Biomed. Mater. Res. 1999, 48, 881-888.

30. Mi, F. L.; Shyu, S. S.; Wong, T. B.; Jang, S. F.; Lee, S. T.; Kuan, C.Y. Chitosan-polyelectrolyte complexation for the preparation of gel beads and controlled release of anticancer drug. II. Effect of $\mathrm{pH}$-dependent ionic crosslinking or interpolymer complex using tripolyphosphate or polyphosphate as reagent. J. Appl. Polym. Sci. 1999, 74, 1093-1107.

31. Kim, S. J.; Shin, S. R.; Kim, N. G.; Kim, S. I. Swelling behavior of semi-interpenetrating polymer network hydrogels based on chitosan and poly(acryl amide). J. Macromol. Sci., Pure Appl. Chem. 2005, A42, 1073-1083.

32. Zhou, S. L.; Matsumoto, S.; Tian, H. D.; Yamane, H.; Ojida, A.; Kiyonaka, S.; Hamachi, I. pHResponsive shrinkage/swelling of a supramolecular hydrogel composed of two small amphiphilic molecules. Chem.-Eur. J. 2005, 11, 1130-1136.

33. Zhang, Y. X.; Wu, F. P.; Li, M. Z.; Wang, E. J. pH switching on-off semi-IPN hydrogel based on cross-linked poly(acrylamide-co-acrylic acid) and linear polyallyamine. Polymer 2005, 46, 76957700 .

34. Mi, F. L.; Liang, H. F.; Wu, Y. C.; Lin, Y. S.; Yang, T. F.; Sung, H. W. pH-sensitive behavior of two-component hydrogels composed of N,O-carboxymethyl chitosan and alginate. J. Biomater. Sci., Polym. Ed. 2005, 16, 1333-1345.

35. Kim, B.; La Flamme, K.; Peppas, N. A. Dynamic swelling Behavior of pH-sensitive anionic hydrogels used for protein delivery. J. Appl. Polym. Sci. 2003, 89, 1606-1613.

36. Ref 27; see also Lin, W. C.; Yu, D. G.; Yang, M. C. pH-sensitive polyelectrolyte complex gel microspheres composed of chitosan/sodium tripolyphosphate/dextran sulfate: swelling kinetics and drug delivery properties. Colloids Surf. B. Biointerfaces 2005, 44, 143-151.

37. see Kobayashi, S.; Tokunoh, M.; Saegusa, T.; Mashio, F. Poly(Allylamine) - Chelating Properties and Resins for Uranium Recovery from Seawater. Macromolecules 1985, 18, 23572361.

38. Oliveira, E. D.; Hirsch, S. G.; Spontak, R. J.; Gehrke, S. H. Influence of polymer conformation on the shear modulus and morphology of polyallylamine and poly(alpha-L-lysine) hydrogels. Macromolecules 2003, 36, 6189-6201. and references cited therein.

39. a) Schneider, H. J.; Liu, T. J.; Lomadze, N. Molecular recognition in a supramolecular polymer system translated into mechanical motion. Angew. Chem. Int. Ed. 2003, 42, 3544-3546; b) Schneider, H. J.; Liu, T. J.; Lomadze, N. Dimension changes in a chemomechanical polymer containing ethylenediamine and alkyl functions as selective recognition units. Eur. J. Org. Chem. 2006, 677-692.

40. Chu, C.-H.; Sakiyama, T.; Yano, T. pH-sensitive swelling of a polyelectrolyte complex gel prepared from xanthan and chitosan. Biosci., Biotechnol., Biochem. 1995, 59, 717-719. 
41. see also Pourjavadi, A.; Hosseinzadeh, H.; Mazidi, R. Modified carrageenan. 4. Synthesis and swelling behavior of crosslinked kappa C-g-AMPS superabsorbent hydrogel with antisalt and pH-responsiveness properties. J. Appl. Polym. Sci. 2005, 98, 255-263.

42. Pourjavadi, A.; Sadeghi, M.; Hosseinzadeh, H. Modified carrageenan. 5. Preparation, swelling behavior, salt- and pH-sensitivity of partially hydrolyzed crosslinked carrageenan-graftpolymethacrylamide superabsorbent hydrogel. Polym. Adv. Technol. 2004, 15, 645-653.

43. Seo, K. W.; Kim, D. J.; Park, K. N. Swelling properties of poly(AM-co-AA)/chitosan pH sensitive superporous hydrogels. J. Indust. Engin. Chem. 2004, 10, 794-800.

44. Schneider, J. P.; Pochan, D. J.; Ozbas, B.; Rajagopal, K.; Pakstis, L.; Kretsinger, J. Responsive hydrogels from the intramolecular folding and self- assembly of a designed peptide. J. Am. Chem. Soc. 2002, 124, 15030-15037, Ozbas, B.; Kretsinger, J.; Rajagopal, K.; Schneider, J. P.; Pochan, D. J. Salt-triggered peptide folding and consequent self-assembly into hydrogels with tunable modulus. Macromolecules 2004, 37, 7331-7337.

45. Watanabe, T.; Ito, K.; Alvarez-Lorenzo, C.; Grosberg, A. Y.; Tanaka, T. Salt effects on multiplepoint adsorption of target molecules by heteropolymer gel. J. Chem. Phys. 2001, 115, 1596-1600.

46. Yamaguchi, S.; Yoshimura, L.; Kohira, T.; Tamaru, S.; Hamachi, I. Cooperation between artificial receptors and supramolecular hydrogels for sensing and discriminating phosphate derivatives. J. Am. Chem. Soc. 2005, 127, 11835-11841.

47. Rao, G. V. R.; Konishi, T.; Ise, N. Ordering in Poly(allylamine hydrochloride) Gels. Macromolecules, 1999, 32, 7582-7586.

48. K. Kato, H.-J. Schneider, unpublished results

49. Kim, B.; La Flamme, K.; Peppas, N. A. Dynamic swelling Behavior of pH-sensitive anionic hydrogels used for protein delivery. J. Appl. Polym. Sci. 2003, 89, 1606-1613.

50. Qu, X.; Wirsen, A.; Albertsson, A. C. Novel pH-sensitive chitosan hydrogels: swelling behavior and states of water. Polymer 2000, 41, 4589-4598, see also Qu, X.; Wirsen, A.; Albertsson, A. C. Structural change and swelling mechanism of $\mathrm{pH}$-sensitive hydrogels based on chitosan and D,Llactic acid. J. Appl. Polym. Sci. 1999, 74, 3186-3192.

51. Barbucci, R.; Magnani, A.; Consumi, M. Swelling behavior of carboxymethylcellulose hydrogels in relation to cross-linking, $\mathrm{pH}$, and charge density. Macromolecules 2000, 33, 7475-7480.

52. Park, H. Y.; Song, I. H.; Kim, J. H.; Kim, W. S. Preparation of thermally denatured albumin gel and its pH-sensitive swelling. Int. J. Pharm. 1998, 175, 231-236.

53. Guan, Y. L.; Shao, L.; Liu, J.; DeYao, K. pH effect on correlation between water state and swelling kinetics of the crosslinked chitosan/polyether semi-IPN hydrogel. J. Appl. Polym. Sci. 1996, 62, 1253-1258.

54. Zhang, Y.; Gu, H. W.; Yang, Z. M.; Xu, B. Supramolecular hydrogels respond to ligand-receptor interaction. J. Am. Chem. Soc. 2003, 125, 13680-13681.

55. Chu, C. H.; Kumagai, H.; Sakiyama, T.; Ikeda, S.; Nakamura, K. Development of a model for analyzing the swelling rate of ionic gels on the basis of the diffusion of mobile ions: Application to the $\mathrm{pH}$-sensitive swelling of a polyelectrolyte complex gel prepared from xanthan and chitosan. Biosci., Biotechnol., Biochem. 1996, 60, 1627-1632.

56. Chu, Y.; Varanasi, P. P.; McGlade, M. J.; Varanasi, S. Ph-Induced Swelling Kinetics of Polyelectrolyte Hydrogels. J. Appl. Polym. Sci. 1995, 58, 2161-2176. 
57. Schneider, H. J.; Tianjun, L.; Lomadze, N. Sensitivity increase in molecular recognition by decrease of the sensing particle size and by increase of the receptor binding site - a case with chemomechanical polymers. Chem. Commun. 2004, 2436-2437.

58. Kopelman, R.; Dourado, S. Is smaller better? - Scaling of characteristics with size of fiber-optic chemical and biochemical sensors. Proc. SPIE-Inter. Soc. Opt. Engin. 1996, 2836, 2-11; Clark, H. A.; Hoyer, M.; Philbert, M. A.; Kopelman, R. Optical Nanosensors for Chemical Analysis inside Single Living Cells. 1. Fabrication, Characterization, and Methods for Intracellular Delivery of PEBBLE Sensors. Analyt. Chem. 1999, 71, 4831-4836.

59. Aguilar, J.; Diaz, P.; Escarti, F.; Garcia-Espana, E.; Gil, L.; Soriano, C.; Verdejo, B. Cation and anion recognition characteristics of open-chain polyamines containing ethylenic and propylenic chains. Inorg. Chim. Acta 2002, 339, 307-316, and references cited therein.

60. See ref 57.

61. Reviews : de Silva, A. P.; Fox, D. B.; Huxley, A. J. M.; Moody, T. S. Combining luminescence, coordination and electron transfer for signalling purposes. Coord. Chem. Rev. 2000, 205, 41-57. Pease, A. R.; Stoddart, J. F. Computing at the molecular level. Molecular Machines and Motors, 2001, 99, 189-236. Raymo, F. M. Digital processing and communication with molecular switches. Adv. Mat. 2002, 14, 401-414. Balzani, V.; Credi, A.; Venturi, M. Molecular logic circuits. ChemPhysChem 2003, 4, 49-59.

62. Schneider, H. J.; Liu, T. J.; Lomadze, N.; Palm, B. Cooperativity in a chemomechanical polymer: A chemically induced macroscopic logic gate. J. Adv. Mater. 2004, 16, 613.

63. For other metal ion-responsive gels see e.g. Ricka, J.; Tanaka, T. Phase-Transition in Ionic Gels Induced by Copper Complexation. Macromolecules 1985, 18, 83-85.

64. Meyer, E. A.; Castellano, R. K.; Diederich, F. Interactions with aromatic rings in chemical and biological recognition. Angew. Chem. Int. Ed. 2003, 42, 1210-1250.

65. Lomadze, N.; Schneider, H. J. A chitosan-based chemomechanical polymer triggered by stacking effects with aromatic effectors including aminoacid derivatives. Tetrahedron Lett. 2005, 61, 8694-8698.

66. Kato, K.; Schneider, H. -J. Langmuir, 2007 accepted.

67. Liu, T. J.; Schneider, H. J. Additivity and quantification of dispersive interactions-from cyclopropyl to nitro groups: Measurements on porphyrin derivatives. Angew. Chem. Int. Ed. Engl. 2002, 41, 1368-1370.

68. Brizard, A.; Oda, R.; Huc, I. Chirality effects in self-assembled fibrillar networks. Top. Curr. Chem. 2005, 256, 167-218. Sugiyasu, K.; Tamaru, S.; Takeuchi, M.; Berthier, D.; Huc, I.; Oda, R.; Shinkai, S. Double helical silica fibrils by sol-gel transcription of chiral aggregates of gemini surfactants. Chem. Commun. 2002, 1212-1213. Goto, H.; Zhang, H. Q.; Yashima, E. Chiral stimuli-responsive gels: Helicity induction in poly(phenylacetylene) gels bearing a carboxyl group with chiral amines. J. Am. Chem. Soc. 2003, 125, 2516-2523.

69. Zhang, Y.; Gu, H. W.; Yang, Z. M.; Xu, B. Supramolecular hydrogels respond to ligand-receptor interaction. J. Am. Chem. Soc. 2003, 125, 13680-13681.

70. Schneider, H. J.; Kato, K. Direct translation of chiral recognition into mechanical motion. Angew. Chem. 2007, 119, 2748 -2750; Angew. Chem. Int. Ed. Engl. 2007, 46, 2694 -2696. 
71. Lomadze, N.; Schneider, H. -J. Ternary complex formation inducing large expansions of chemomechanical polymers by metal chelators, aminoacids and peptides as effectors. Tetrahedron Lett. 2005, 46, 751-754.

72. See e.g. Sigel, H.; Martin, R. B. Coordinating Properties of the Amide Bond - Stability and Structure of Metal-Ion Complexes of Peptides and Related Ligands. Chem. Rev. 1982, 82, 385426. E. Farkas and I. Sóvágó, Metal Complexes of Amino Acids and Peptides. Amino Acids, Pept. Prot. 2006, 35, 353-435. Aoki, S.; Kimura, E. Zinc-nucleic acid interaction. Chem. Rev. 2004, 104, 769-787. Licini, G.; Scrimin, P. Metal-ion-binding peptides: From catalysis to protein tagging. Angew. Chem. Int. Ed. 2003, 42, 4572-4575.

73. See e.g. a) Canary, J. W.; Gibb, B. C. Selective recognition of organic molecules by metallohosts. Progr. Inorg. Chem. 1997, 45, 1-81. b) Raymo, F. M.; Stoddart, J. F. Secondsphere coordination. Chem. Ber. 1996, 129, 981-990; c) Steed, J. W. First- and second-sphere coordination chemistry of alkali metal crown ether complexes. Coord. Chem. Rev. 2001, 215, 171-221. d) Fabbrizzi, L.; Licchelli, M.; Mancin, F.; Pizzeghello, M.; Rabaioli, G.; Taglietti, A.; Tecilla, B.; Tonellato, U. Fluorescence sensing of ionic analytes in water: From transition metal ions to Vitamin B13. Chem. Eur. J. 2002, 8, 94-101.

74. Reviews: a) Mohr, G. J. Covalent bond formation as an analytical tool to optically detect neutral and anionic analytes. Sens. Actuators, B 2005, 107, 2-13. b) Mohr, G. J. New chromogenic and fluorogenic reagents and sensors for neutral and ionic analytes based on covalent bond formation - a review of recent developments. Anal. Bioanal. Chem. 2006, 386, 1201-1214.

75. Kitano, Y.; Koyama, K.; Kataoka, O.; Kazunori; T.; Okano, Y.; Sakurai, Y. A novel drug delivery system utilizing a glucose responsive polymer complex between poly (vinyl alcohol) and poly (N-vinyl-2-pyrrolidone) with a phenylboronic acid moiety. J. Controlled Release 1992, 19, 161-170.

76. Selected recent reviews: a) James, T. D.; Shinkai, S. Artificial receptors as chemosensors for carbohydrates. Top. Curr. Chem. 2002, 218: 159-200. b) Wang W.; Gao, X. M.; Wang, B. H. Boronic acid-based sensors. Curr. Org. Chem. 2002, 6, 1285-1317. c) Striegler, S. Selective carbohydrate recognition by synthetic receptors in aqueous solution. Curr. Org. Chem. 2003, 7, 81-102. d) Cao, H. S.; Heagy, M. D. Fluorescent chemosensors for carbohydrates: A decade's worth of bright spies for saccharides in review. J. Fluoresc. 2004, 14, 569-584. e) Pickup, J. C.; Hussain, F. Evans, N. D.; Rolinski, O. J.; Birch, D. J. S. Fluorescence-based glucose sensors. Biosens. Bioelectron. 2005, 20, 2555-2565. f) Yan, J.; Fang, H.; Wang, B. H. Boronolectins and fluorescent boronolectins: An examination of the detailed chemistry issues important for the design. Med. Res. Rev. 2005, 25, 490-520, Hilt, J. Z.; Byrne, M. E.; Peppas, N. A. Microfabrication of intelligent biomimetic networks for recognition of D-glucose. Chemistry of Materials 2006, 18, 5869-5875.

77. a) James, T. D.; Sandanayake, K. R. A. S.; Shinkai, S. A glucose-selective molecular fluorescence sensor. Angew Chem. Int. Ed. Engl. 1994, 33, 2207-2209; b) Eggert, H.; Frederiksen, J.; Morin, C.; Norrild, J. C. A new glucose-selective fluorescent bisboronic acid. First report of strong alpha-furanose complexation in aqueous solution at physiological $\mathrm{pH} . J$. Org. Chem. 1999, 64, 3846-3852. 
78. Alexeev, V. L.; Sharma, A. C.; Goponenko, A. V.; Das, S.; Lednev, I. K.; Wilcox, C. S.; Finegold, D. N.; Asher, S. A. High ionic strength glucose-sensing photonic crystal. Anal. Chem. 2003, 75, 2316-2323.

79. Samoei, G. K.; Wang, W. H.; Escobedo, J. O.; Xu, X.; Schneider, H.-J.; Cook, R. L,; Strongin, R. M. A chemomechanical polymer that functions in blood plasma with high glucose selectivity. Angew. Chem. Int. Ed. Engl. 2006, 45, 5319-5322.

80. Choi, Y. K.; Jeong, S. Y.; Kim, Y. H. A glucose-triggered solubilizable polymer gel matrix for an insulin delivery system. Int. J. Pharm. 1992, 80, 9-16.

81. Shiino, D.; Kataoka,, K.; Koyama, Y.; Yokoyama, M.; Okano, T.; Sakurai, Y. A self-regulated insulin delivery system using boronic acid gel. J. Intell. Mater. Syst. Struct. 1994, 311-314.

82. Shiino, D.; Murata, Y.; Kubo, A.; Kim, Y. J.; Kataoka, K.; Koyama, Y.; Kikuchi, A.; Yokoyama, M.; Sakurai, Y.; Okano, T. Amine containing phenylboronic acid gel for glucose-responsive insulin release under physiological pH. J. Control. Release 1995, 37, 269-276.

83. Kikuchi, A.; Suzuki, K.; Okabayashi, O.; Hoshino, H.; Kataoka, K.; Sakurai, Y.; Okano, T. Glucose-sensing electrode coated with polymer complex gel containing phenylboronic acid. Anal. Chem. 1996, 68, 823-828.

84. Arnold, F. H.; Zheng, W. G.; Michaels, A. S. A membrane-moderated, conductimetric sensor for the detection and measurement of specific organic solutes in aqueous solutions. J. Membr. Sci. 2000, 167, 227-239.

85. Hisamitsu, I.; Kataoka, K.; Okano, T.; Sakurai, Y. Glucose-responsive gel from phenylborate polymer and poly(vinyl alcohol): Prompt response at physiological $\mathrm{pH}$ through the interaction of borate with amine group in the gel. Pharm. Res. 1997, 14, 289-293.

86. Kataoka, K.; Miyazaki, H.; Bunya, M.; Okano, T.; Sakurai, Y. Totally synthetic polymer gels responding to external glucose concentration: Their preparation and application to on-off regulation of insulin release. J. Am. Chem. Soc. 1998, 120, 12694-12695.

87. Matsumoto, A.; Ikeda, S.; Harada, A.; Kataoka, K. Glucose-responsive polymer bearing a novel phenylborate derivative as a glucose-sensing moiety operating at physiological $\mathrm{pH}$ conditions. Biomacromolecules 2003, 4, 1410-1416.

88. Matsumoto, A.; Yoshida, R.; Kataoka, K. Glucose-responsive polymer gel bearing phenylborate derivative as a glucose-sensing moiety operating at the physiological $\mathrm{pH}$. Biomacromolecules 2004, 5, 1038-1045.

89. Matsumoto, A.; Kurata, T.; Shiino, D.; Kataoka, K. Swelling and shrinking kinetics of totally synthetic, glucose-responsive polymer gel bearing phenylborate derivative as a glucose-sensing moiety. Macromolecules 2004, 37, 1502-1510.

90. Reviews: a) Gronwald, O.; Snip, E.; Shinkai, S. Gelators for organic liquids based on selfassembly: a new facet of supramolecular and combinatorial chemistry. Curr. Opin. Colloid Interface Sci. 2002, 7, 148-156. b) Jung, J. H.; Shinkai, S. Gels as templates for nanotubes. Top. Curr. Chem. 2004, 248, 223-260.

91. Kanekiyo, Y.; Inoue, K.; Ono, Y.; Sano, M.; Shinkai, S.; Reinhoudt, D. N. 'Molecular-imprinting' of AMP utilising the polyion complex formation process as detected by a QCM system. J. Chem. Soc., Perkin Trans. 2 1999, 2719-2722. 
92. Kanekiyo, Y.; Sano, M.; Iguchi, R.; Shinkai, S. Novel nucleotide-responsive hydrogels designed from copolymers of boronic acid and cationic units and their applications as a QCM resonator system to nucleotide sensing. J. Polym. Sci., Part A: Polym. Chem. 2000, 38, 1302-1310.

93. Gabai, R.; Sallacan, N.; Chegel, V.; Bourenko, T.; Katz, E.; Willner, I. Characterization of the swelling of acrylamidophenylboronic acid-acrylamide hydrogels upon interaction with glucose by faradaic impedance spectroscopy, chronopotentiometry, quartz-crystal microbalance (QCM), and surface plasmon resonance (SPR) experiments. J. Phys. Chem. B 2001, 105, 8196-8202.

94. Ong, K. G.; Paulose, M.; Jain, M. K.; Gong, D.; Vargheses, O. K.; Mungle, C.; Grimes, C. A. Magnetism-based remote query glucose sensors. Sensors 2001, 1, 138-147.

95. Asher, S. A.; Alexeev, V. L.; Goponenko, A. V.; Sharma, A. C.; Lednev. I. K.; Wilcox, C. S.; Finegold, D. N. Photonic crystal carbohydrate sensors: Low ionic strength sugar sensing. J. Am. Chem. Soc. 2003, 125, 3322-3329.

96. Lee, Y. J. ; Pruzinsky, S. A. ; Braun, P. V. Glucose-sensitive inverse opal hydrogels: Analysis of optical diffraction response. Langmuir 2004, 20, 3096-3106.

97. Ben-Moshe, M.; Alexeev V. L.; Asher, S. A. Fast responsive crystalline colloidal array photonic crystal glucose sensors. Anal. Chem. 2006, 78, 5149-5157.

98. Kabilan, S.; Blyth, J.; Lee, M. C.; Marshall, A. J.; Hussain, A.; Yang, X. P.; Lowe, C. R. Glucose-sensitive holographic sensors. J. Inclusion Phenom. Mol. Recognit. Chem. 2004, 17, $162-166$

99. Lee, M. C.; Kabilan, S.; Hussain, A.; Yang, X. P.; Blyth, J.; Lowe, C. R. Glucose-sensitive holographic sensors for monitoring bacterial growth. Anal. Chem. 2004, 76, 5748-5755.

100. Kabilan, S.; Marshall, A. J.; Sartain, F. K.; Lee, M. C.; Hussain, A.; Yang, X. P.; Blyth, J.; Karangu, N.; James, K.; Zeng, J.; Smith, D.; Domschke, A.; Lowe, C. R. Holographic glucose sensors. Biosens. Bioelectron. 2005, 20, 1602-1610.

101. Yang, X. P.; Lee, M. C.; Sartain, F.; Pan, X. H.; Lowe, C. R. Designed boronate ligands for glucose-selective holographic sensors. Chem. Eur. J. 2006, 12, 8491-8497.

102. For example: Beebe, D. J.; Moore, J. S.; Bauer, J. M.; Yu, Q.; Liu, R. H.; Devadoss, C.; Jo, B. H. Functional hydrogel structures for autonomous flow control inside microfluidic channels. Nature 2000, 404, 588-596.

103. a) Nakamura, K.; Murray, R. J.; Joseph, J. I.; Peppas, N. A.; Morishita, M.; Lowman, A. M. Oral insulin delivery using P(MAA-g-EG) hydrogels: effects of network morphology on insulin delivery characteristics. J. Controlled Release 2004, 95, 589-599; b) Morishita, M.; Goto, T.; Peppas, N. A.; Joseph, J. I.; Torjman, M. C.; Munsick, C.; Nakamura, K.; Yamagata, T.; Takayama, K.; Lowman, A. M. Mucosal insulin delivery systems based on complexation polymer hydrogels: effect of particle size on insulin enteral absorption. J. Controlled Release 2004, 97, 115-124.

(C) 2007 by MDPI (http://www.mdpi.org). Reproduction is permitted for noncommercial purposes. 